\title{
İzmir Orman Bölge Müdürlüğü fıstıkçamı (Pinus pinea L.) meşcereleri için gövde hacim tablolarının düzenlenmesi
}

Construction of stem volume tables for stone pine (Pinus pinea L.) stands in İzmir Regional Directorate of Forestry

\author{
Niyazi ÖZÇANKAYA ${ }^{1}$ (iD \\ Mustafa BATUR ${ }^{1}$ \\ Özgür KİRACIOĞLU²
}

Sorumlu yazar (Corresponding author) Niyazi ÖZÇANKAYA

n_ozcankaya@yahoo.com

Geliş tarihi (Received)

21.12.2020

Kabul Tarihi (Accepted)

16.02.2021

Sorumlu editör (Corresponding editor) Neşat ERKAN

nesaterkan@yahoo.com

Atıf (To cite this article): Özçankaya, N , Batur, M , Kiracıoğlu, Ö . (2021). İzmir Orman Bölge Müdürlüğü fistıkçamı (Pinus pinea L.) meşcereleri için gövde hacim tablolarının düzenlenmesi . Ormancılık Araştırma Dergisi , 8 (2), 125-145 DOI: https://doi.org/10.17568/ogmoad. 813362

\section{$\ddot{O} z$}

Bu çalışmada İzmir Orman Bölge Müdürlüğü (OBM) sınırları içinde kullanılmak üzere, varlığ ve ekonomik değeri ile önemli bir orman ağacı türü olan fistıkçamı (Pinus pinea L.)'nın tek ve çift girişli dikili kabuklu gövde hacim tabloları düzenlenmiştir. Bu amaçla, İzmir OBM genelinde 275 adet örnek ağaçta ölçüm yapılarak gerekli veri elde edilmiştir. Ağaçların 44'ü kontrol ve 231'i model geliştirme grubu olarak ayrılmıştır. En uygun hacim için modellerin belirlenmesinde Ortalama Hata, Ortalama Mutlak Hata, Hataların Standart Sapması, Açıklanan Varyans Yüzdesi, Toplam Hata Yüzdesi, Ortalama Mutlak Hata Yüzdesi ve Ortalama (Vasati) Ayrılış Yüzdesi gibi başarı ölçütleri yanında artık değerlerin analizlerinden yararlanılmıştır. Seçilen hacim modellerinin, $\alpha=0,05$ anlam düzeyinde İzmir OBM fistıkçamı ormanlarında kullanımlarının uygun olduğu anlaşılmıştır. İzmir OBM tek girişli gövde hacim tabloları "lo $g V=\beta_{0}+\beta_{I *} \log d+\beta_{2 *}(\log d)^{4}+\beta_{3 *}(1 / d)$ ", çift girişli gövde hacim tablolar1 ise " $\log V=\beta_{0}+\beta_{1^{*}} \log \left(d^{2} h\right)+\beta_{2^{*}}(1 /(h+6))^{2}+\beta_{3^{*}}(1 / d h)$ " denklemleriyle düzenlenmiştir.

Anahtar Kelimeler: Fıstıkçamı, gövde hacim tablosu, hacim modeli, başarı ölçütleri

\begin{abstract}
In this study, single and double entry tree volume tables of stone pine (Pinus pinea L.), which is an important forest tree species in terms of existence and economic value, were prepared to be used within the boundaries of İzmir Regional Directorate of Forestry (İzmir RDF). For this purpose, 275 sample trees were taken from the İzmir RDF and necessary data were obtained. 44 of the sample trees were separated as control and 231 as model development group. The models for the most appropriate volume were determined using the criteria of Mean Error, Mean Absolute Error, Standard Deviation of Errors, Percent of Variance Described, Total Failure Percentage, and Average Absolute Failure Percentage and also the analysis of residual values were utilized. It has been determined that the selected volume models are fixed to use in İzmir RDF pine forests at the significance level of $\alpha<0,05$. Single and double entry volume tables were produced with the "lo $g V=\beta_{0}+\beta_{I^{*}} \log d+\beta_{2^{*}}(\log d)^{4}+\beta_{3^{*}}(1 / d)$ " and " $\log V=\beta_{0}+\beta_{I^{*}} \log \left(d^{2} h\right)+\beta_{2^{*}}(1 /$ $(h+6))^{2}+\beta_{3 *}(1 / d h)$ " equations, respectively.
\end{abstract}

Key words: Stone pine tree, tree volume table, volume model, success criteria 


\section{Giriş}

Orman İşletmelerinin en önemli sermayelerinden birisi meşceredeki dikili tek ağaç hacimlerinin toplamı olan ağaç servetidir (Kalıpsız, 1984; Yavuz, 1999). Sürdürülebilir ve rasyonel orman yönetimi planlama ile mümkündür. Orman amenajman planlarının temel dayanağı meşceredeki hacim ve artım değerleridir. Bu değerlerin doğru ve güvenilir olması uygulanabilir bir plan için önemli bir gerekliliktir.

Tek ağaç ve meşcere hacim değerlerinin analitik yöntemlerle hesaplanması ağaçlar kesilmeden mümkün olmamaktadır (Sakıcı ve ark., 2018). Dikili ağaçların gövde hacim değerlerini saptamak için her saferinde kesim yapılamayacağından, hacim değerleri geliştirilen daha pratik yöntemler ile tahmin edilmektedir (Fırat, 1973; Kalıpsız, 1984; Yavuz, 1999). Tahminler, ağaç türleri için uygun değerler üreten, istatistik yöntemlerle elde edilmiş modeller ile gerçekleştirilir ve en uygun denklemler, birçok denklem arasından uygunluk testleri yardımıyla seçilir (Kalıpsız, 1984; Carus ve Su, 2014).

Ağacın kolay biçimde ölçüm değerlerinin elde edilebileceği kısımlarının (çap, çap ve boy vd.) birer bağımsız değişken olduğu bu denklemlerden dikili kabuklu gövde hacim tabloları (DKGHT) türetilir (Kalıpsız, 1984). Hacim denklemleri kullanılan bağımsız değişken sayısına bağlı olarak tek, çift ve çok girişli olarak (Loetsch ve ark., 1973; Kalıpsız, 1984); bununla beraber kullanıldıkları alanın büyüklüğüne göre de yöresel, bölgesel ve genel olmak üzere üçer farklı biçimde gruplandırılmışlardır (Köhl ve ark, 2006; Sakıcı ve ark., 2018).

Ormancılıkta ağaç serveti envanteri çalışmalarında, örnek alanların hacimlerinin kestirilmesinde genel olarak tek (çap) veya çift (çap-boy) girişli gövde hacim tabloları kullanılmaktadır. Orman amenajman planlarındaki artım ve servet hesaplarının doğru yapılabilmesi için tek ağaçlar için mümkün olduğu ölçüde doğru hacim veren dikili kabuklu gövde hacim tablolarına (DKGHT) ihtiyaç vardır.

İzmir Orman Bölge Müdürlüğü (OBM) kapsamında fıstıkçamı meşcerelerine sahip plan ünitelerinin orman amenajman planlarında fistıkçamı ağaç türü için tek girişli hacim ve artım tabloları mevcuttur. Ancak geçmiş planlama dönemlerinde grafik yöntemlerle hazırlanmış bu tabloların kökeni belirsizdir ve genel olarak düşük hacim değerleri tahmin etmektedir. Uygulayıcılar tarafından tabloların problemli değerleri öne sürülerek tekrar düzenlenmelerinin gerekliliği sıklıkla vurgulanmaktadır.

Fıstıkçamı (Pinus pinea L.) her ne kadar yenilebilir lezzetli tohumlara sahip olduğu için tüm dünyada değerli kabul edilse de odun özellikleri ile de ekonomik öneme sahip bir ağaç türüdür. Odunu hoş kokulu ve terebentin içeriği yüksektir. Direk, travers, kaplama, ambalaj ve yapı malzemesi, mobilya, doğrama, gemi-tekne yapımı, lif yonga, levha, reçine, selüloz ve kağıt endüstrisinde kullanılmaktadır (Doğu ve ark., 2002).

Türün doğal yayılış alanı Akdeniz Havzası 1lıman iklim kuşağıdır. En geniş yayılışını İspanya'da, en büyük yayılışını ise Türkiye, Portekiz, İtalya, Fransa, Yunanistan, Arnavutluk, Suriye, Fas, Tunus ve Cezayir'de yapmaktadır (Fady ve ark., 2004). Ülkemizde ise doğal olarak İzmir-Bergama-Kozak Havzasında, Aydın-Koçarlı-Mazon Bölgesinde ve Muğla-Yatağan-Katrancı Havzası'nda büyük meşcereler halinde bulunmaktadır (Firat, 1943; Kılc1 ve ark., 2000).

İzmir-Bergama-Kozak havzasında bulunan fıstıkçamı meşcereleri ülkemiz ve İzmir OBM için büyük önem taşımaktadır. Yüksek verimli fıstıkçamı ormanları bu yörede bulunmakta olup, ülkemizdeki doğal fıstıkçamı sahalarının \%31,4'üne karşılık gelmektedir (Kılcı ve ark., 2014). Orman Genel Müdürlüğü (OGM) 2019 Türkiye Orman Varlığı istatistiklerine göre 131.550 ha normal koru, 33.250 ha ise bozuk koru olmak üzere toplam 164.800 ha fistıkçamı ormanı bulunmaktadır (OGM, 2019). Ancak, devlet ormanı sınırları dışında olan Kozak yöresinde yaklaşık 30.000 ha ve diğer bölgelerdeki özel fistıkçamı ormanları, amenajman planlarında ziraat rumuzuyla gösterildiğinden bu alana dâhil değildir.

Asli ağaç türlerimizin çoğu için hacim tabloları düzenlenmiştir. Farklı ağaç türleri için grafik (Erkin, 1948; Eraslan, 1954; Gülen, 1959; Kalıpsız, 1962) ve matematik (Miraboğlu, 1955; Alemdağ, 1962; Akalp, 1978; Asan, 1984) yöntemler kullanılarak yapılan çalışmalar ile genel (Alemdağ, 1967; Sun ve ark., 1978; Bozkuş ve Carus, 1997) ve yöresel/ bölgesel (Erdemir, 1974; Erkan, 1997; Saraçoğlu, 1998, Yavuz, 1999; Sakıc1 ve Yavuz, 2003; Ercan11 ve ark., 2008; Özçelik, 2010; Kahriman ve ark., 2017) ölçeklerde hacim tabloları üretilmiştir.

Fıstıkçamının planlaması ve hasılatına yönelik araştırmalar ise oldukça kısıtlıdır. "Fıstıkçamı ormanlarımızda meyva ve odun verimi bakımından araştırmalar ve bu ormanların amenajman esasları" isimli ilk çalışma Fırat (1943) tarafından yapılmıştır. Ayrıca Eler (1986)'in Antalya Bölgesi fıstıkçamı ağaçlandırma alanlarındaki fıstık ve odun verimine ilişkin çalışması ile Güler (2010)'in Antalya ağaçlandırma sahaları için Yöresel Fıstıkçamı DKGHT düzenlediği çalışma bulunmaktadır. 
Çalışmanın amacı, İzmir OBM genelinde fıstıkçamı ağaç türü için güvenle kullanılabilecek tek ve çift girişli dikili kabuklu gövde hacim modellerinin geliştirilmesi ve tablolarının düzenlenmesidir.

\section{Materyal ve Yöntem}

\subsection{Materyal}

Araştırma alanı İzmir OBM'dir. Çalışma materyalini fıstıkçamı meşcerelerinden seçilmiş 275 adet örnek ağaç ve orman amenajman planları oluşturmaktadır. Örnek ağaçların dağılımı kurgulanırken İzmir OBM'ne bağlı Orman İşletme Müdürlüklerinde bulunan fistıkçamı meşcereleri alanlarının, İzmir OBM fistıkçamı meşcereleri toplam alanlarına oranları (Bektaş, 2012) dikkate alınmıştır (Tablo 1).

\subsection{Yöntem}

Gövde hacim denklemlerinin üretilmesinde regresyon analizi yöntemi kullanılmıştır. Alternatif

Tablo 1 Orman İşletme Müdürlüklerinin toplam fistıkçamı alanları, İzmir OBM fıstıkçamı toplam alanına oranları ve ölçülen örnek ağaç sayıları

Table 1. Total stone pine areas of Forest Management Directorates, their ratio to the total area of Izmir RDF stone pine and the number of sample trees measured

\begin{tabular}{cccc}
\hline $\begin{array}{c}\text { Orman İşletme } \\
\text { Müdürlüğü }\end{array}$ & $\begin{array}{c}\text { F1stıçamı Sahası } \\
(\text { ha) }\end{array}$ & $\%$ & $\begin{array}{c}\text { Örnek Ağaç } \\
\text { Sayı1s }\end{array}$ \\
\hline Akhisar & $3.216,1$ & 6,6 & 20 \\
Bayındır & $4.032,7$ & 8,3 & 22 \\
Bergama & $20.758,0$ & 42,7 & 134 \\
Demirci & $4.687,2$ & 9,7 & 12 \\
Gördes & $2.395,3$ & 4,9 & 12 \\
İzmir & $2.225,1$ & 4,6 & 12 \\
Manisa & $9.760,1$ & 20,1 & 49 \\
Menderes & $1.526,5$ & 3,1 & 14 \\
Toplam & $48.601,0$ & 100,0 & 275 \\
\hline
\end{tabular}

denklemler başarı ölçütleri ile değerlendirilmiş, seçilen en uygun denklemlerin ürettiği değerler ile hacim tabloları düzenlenmiştir.

Hacim tablolarının düzenlenmesinde veya hacim denklemlerinin geliştirilmesinde üç önemli iş aşaması olduğu belirtilmiştir (Yavuz, 1995). Bunlar;

- Yeterli sayıda ve uygun örnek ağaç seçimi,

- Hacim denklemlerinin düzenlenebilmesi için bağımlı (ağaç gövde hacmi) ve bağımsız (göğüs çapı ve ağaç boyu) değişkenlerin ölçümü,

- Model formunun seçimi ve modelin test edilmesiyle en uygun hacim denkleminin seçimidir.

\subsection{1. Örnek ağaçların seçimi}

Herhangi bir ağaç türü için düzenlenecek hacim tablolarının hazırlanması aşamalarında, öncelikle ilgili türün doğal yayılış gösterdiği meşcerelerden yeterli sayıda ve uygun nitelikte örnek ağaçların seçilmesi gerekmektedir. Örnek ağaçların düzgün gövdeli, sağlıklı, canlı ve sağlam tepeli olmalarına dikkat edilmiş, farklı çap ve boy kademelerine dağılımlarının da yeterli olması gözetilmiştir.

\subsubsection{Hacim değerlerinin hesaplanması}

Çalışmada örnek ağaç gövde hacimlerinin belirlenmesi için seksiyon (bölümleme) yöntemi ve "Smalian Hacim Formülü” uygulanmıştır. Seksiyon uzunluğu kısaldıkça hacmin güvenirliliği artmakta olduğundan bu uzunluk 1,0 metre (m) olarak seçilmiştir.

Örnek ağaçlar toprak seviyesinden kesilmiş, ölçü işlemleri için dalları kesilerek gövde temizlenmiştir. Çap ölçümleri, gövdenin dip kısmından tepe ucuna kadar, mümkün olduğunca düzenli bir şekilde 0,3 m'den başlayarak $1 \mathrm{~m}$ aralıklarla $(0,3 \mathrm{~m}$, $1,3 \mathrm{~m}, 2,3 \mathrm{~m}, 3,3 \mathrm{~m}$ ve 4,3 $\mathrm{m}$ gibi), birbirine dik şekilde çift taraflı ve 0,1 santimetre $(\mathrm{cm})$ hassasiyetinde yapılmıştır. Dal şişkinliklerine rastlayan ölçüm yerlerinde ise gerekli düzenlemeler yapılmıştır. Uçta kalan 1 metreden küçük gövde ucunun boyu da ölçülerek kaydedilmiş ve ölçü işlemleri tamamlanmıştır.

Yönteme göre ağaçlar dip kütük $\left(V_{D K}\right)$, dip kütük ile uç parça arasında kalan $\mathrm{n}$ adet 1,0 m'lik seksiyonlar $\left(V_{S T}\right)$ ve uç parça $\left(V_{U P}\right)$ olmak üzere üç bölüme ayrilmış, dip kütüğün silindir ve uç parçanın ise koni biçiminde olduğu varsayılarak her bir bö- 
lüm için kabuklu hacimler ayrı ayrı hesaplanmıştır (Denklem 2.1, 2.2 ve 2.3).

$$
\begin{aligned}
& V_{D K}=\frac{\pi}{4} * d_{0,3}^{2} * 0,3 \\
& V_{S T}=\sum_{i=1}^{n}\left\{\frac{\pi}{4} * \frac{d_{a i}^{2}+d_{\mathrm{u} i}^{2}}{2} * l\right\} \\
& V_{U P}=\frac{1}{3} * \frac{\pi}{4} d_{\ddot{\mathrm{u}} n}^{2} * h_{u \varsigma}
\end{aligned}
$$

Burada, $d_{0,3}: 0,3$ m kütük çapını, $n$ : toplam seksiyon sayısını, $d_{a i}: i$. seksiyon alt yüzeyinin çapını, $d_{u i i}: i$. seksiyon üst yüzeyinin çapını, $l$ : seksiyon uzunlu-

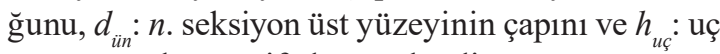
parça uzunluğunu ifade etmektedir.

Her bir gövde bölümü $\left(V_{D K}, V_{S T}\right.$ ve $\left.V_{U P}\right)$ hacimleri toplamı hesaplanarak kabuklu gövde hacimleri
$\left(V_{G}\right)$ tespit edilmiştir (Denklem 2.4).

$$
V_{G}=V_{D K}+V_{S T}+V_{U P}
$$

\subsection{3. İstatistik modellerin belirlenmesi}

Çalışma kapsamında, çoğunlukla literatürdeki benzer çalışmalardan derlenmiş, kısmen de dağıl1ma uygun formlarda düzenlenmiş 25 adet tek (Ek Tablo 1) ve 49 adet çift girişli model (Ek Tablo 2) test edilmiştir.

Kontrol grubu olarak kullanılmak üzere 275 adet ağaçtan rastgele belirlenen \%16's1 (44 adedi) ayrıldiktan sonra, regresyon analizi için 231 adet ağaç kullanılmıştır. Model geliştirme ve kontrol için kullanılan ağaç gruplarına ait bazı istatistikler ile göğüs çapı-ağaç hacmi dağılım grafiği Tablo 2 ve Şekil 1'de verilmiştir.

Tablo 2 İzmir OBM model ve kontrol verilerine ait bazı istatistikler

Table 2. Some statistics of Izmir RDF model and control data

\begin{tabular}{lrrrrrr}
\hline & \multicolumn{3}{c}{ Model Geliştirme Verileri } & \multicolumn{3}{c}{ Kontrol Verileri } \\
\hline & $\begin{array}{c}\text { Göğüs çap1 } \\
(\mathrm{cm})\end{array}$ & $\begin{array}{c}\text { Boy } \\
(\mathrm{m})\end{array}$ & $\begin{array}{c}\text { Hacim } \\
\left(\mathrm{m}^{3}\right)\end{array}$ & $\begin{array}{c}\text { Göğüs çap1 } \\
(\mathrm{cm})\end{array}$ & $\begin{array}{c}\text { Boy } \\
(\mathrm{m})\end{array}$ & $\begin{array}{c}\text { Hacim } \\
\left(\mathrm{m}^{3}\right)\end{array}$ \\
\hline Minimum & 5,35 & 2,46 & 0,005 & 5,15 & 2,62 & 0,007 \\
Maksimum & 112,75 & 26,20 & 12,625 & 93,50 & 24,85 & 8,487 \\
Ortalama & 31,930 & 11,524 & 1,010 & 31,901 & 11,695 & 1,002 \\
Standart sapma & 21,512 & 5,882 & 1,844 & 20,616 & 6,084 & 1,639 \\
Say1 & 231 & 231 & 231 & 44 & 44 & 44 \\
\hline
\end{tabular}

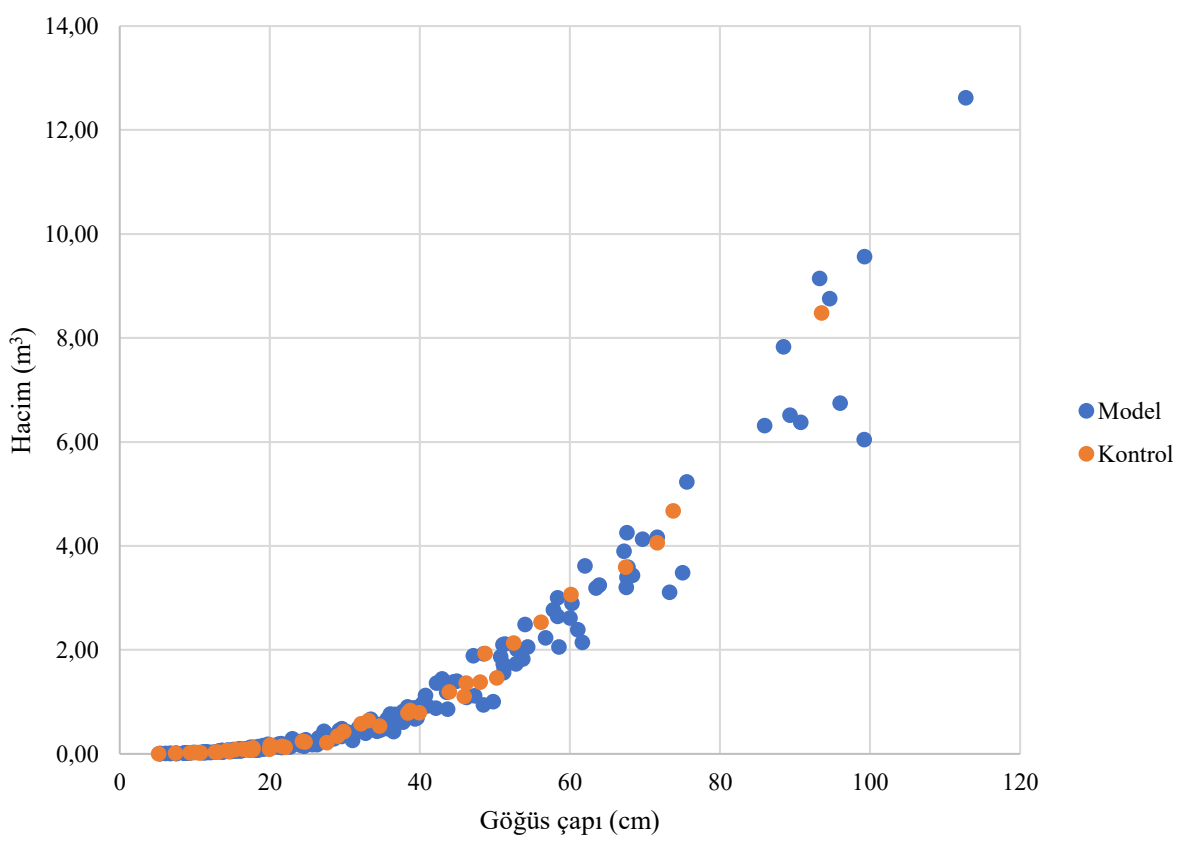

Şekil 1. İzmir OBM için model ve kontrol verilerinin göğüs çapı-hacim dağılımı grafiği Figure 1. Breast diameter-volume distribution graph of model and control data for Izmir RDF 


\subsubsection{En uygun modelin seçimi}

En uygun modelin seçimi iki ana aşamada gerçekleştirilmiştir. İlk aşamada en iyi sonuç veren hacim denklemlerinin seçiminde Ortalama Hata (D) $)$, Ortalama Mutlak Hata $(|\overline{\mathrm{D}}|)$, Hataların Standart Sapması (SD), Açıklanan Varyans Yüzdesi (\%PVE), Toplam Hata Yüzdesi (\%TH) ve Ortalama Mutlak Hata Yüzdesi $(\% \mathrm{MH})$ olmak üzere altı ölçütten oluşan set kullanılmıştır (Denklem 2.5-2.10).

$$
\begin{aligned}
& \bar{D}=\frac{1}{n} *\left(\sum_{i=1}^{n} D_{i}\right) \\
& |\bar{D}|=\frac{1}{n} *\left(\sum_{i=1}^{n}\left|D_{i}\right|\right) \\
& S D=\sqrt{\frac{\left(\sum_{i=1}^{n} D_{i}^{2}\right)-\left(\left(\sum_{i=1}^{n} D_{i}\right)^{2} / n\right)}{(n-1)}} \\
& \% P V E=\left\{\frac{\sum_{i=1}^{n}\left(V_{i}-V_{\text {ort }}\right)^{2}-\sum_{i=1}^{n} D_{i}^{2}}{\sum_{i=1}^{n}\left(V_{i}-V_{\text {ort }}\right)^{2}}\right\} * 100 \\
& \% T H=\left\{\frac{\sum_{i=1}^{n}\left(V_{i}-\widehat{V}_{l}\right)}{\sum_{i=1}^{n} V_{i}}\right\} * 100 \\
& \% M H=\left\{\frac{\sum_{i=1}^{n}\left|V_{i}-\widehat{V}_{l}\right|}{\sum_{i=1}^{n} V_{i}}\right\} * 100
\end{aligned}
$$

Burada; $D_{i}=\left(V_{i}-\widehat{V_{l}}\right)$, ölçülen ve tahmin edilen $i$. değerler arasındaki farkı, $\widehat{V}_{l}$ : denklem ile tahmin edilen $i$. ağaç hacmini, $V_{i}$ : ölçülen $i$. ağaç hacmini, $V_{\text {ort }}$ : ölçülen ağaç hacmi ortalamasını, $n$ : örnek ağaç adedini ifade etmektedir.

Bağımlı değişkenin logaritmik formlu olduğu denklemler için, sistematik hatayı gidermek üzere kullanılan düzeltme faktörleri $(f)$ adi logaritma için Denklem 2.11 ve doğal logaritma için Denklem 2.12 ile hesaplanmıştır (Alemdağ, 1962; Asan, 1984; Çatal, 2005).

$$
\begin{aligned}
& f=10^{\left(1,1513 * S E^{2}\right)} \\
& f=e^{\left(0,5 * S E^{2}\right)}
\end{aligned}
$$

Burada; $f$ : düzeltme faktörünü, $e$ : doğal logaritma tabanını $(\approx 2,71828182)$ ve $S E$ : tahminin standart hatasını ifade etmektedir.

Güvenilir bir hacim fonksiyonunun bu ölçüt değerlerinden ortalama hata, ortalama mutlak hata, hataların standart sapması, toplam hata yüzdesi ve ortalama mutlak hata yüzdesi değerlerinin sıfıra en yakın şekilde küçük, açıklanan varyans yüzdesi ve belirtme katsayısı değerinin ise büyük olması arzu edilir. Ancak; bu ölçüt değerlerinden bir ya da birkaçına göre iyi sonuç veren bir hacim fonksiyonu diğer ölçüt değerlerine göre farklı sonuçlar verebilir. $\mathrm{Bu}$ durumda; hacim fonksiyonları arasında her bir ölçüt değerine göre karşılaştırma yapmak yerine, ölçüt değerlerinin tümünü kapsayacak biçimde bir başarı sıralaması yapılması gerekir.

Uygunluk ölçütlerine göre en uygun regresyon modelinin belirlenmesinde; her bir ölçüt ile modellere başarı sıra numarası verilip, sıra numaraları toplamına (rank değeri) bağlı olarak da en uygun modelin belirlenmesi önerilmektedir (Yavuz, 1999). Bu çalışmada da öncelikle aynı yöntem uygulanmıştır. Ortalama hata, ortalama mutlak hata, hatalarin standart sapması, toplam hata yüzdesi ve ortalama mutlak hata yüzdesi değerlerinin sıfıra en yakın şekilde küçügüüne; açıklanan varyans yüzdesi değerlerine göre ise en büyügüune 1 (bir) sıra numarası verilmiştir. Daha sonra giderek artan bir biçimde her ölçüt değerine göre hacim fonksiyonlarına sıra numarası verilmiş ve sıra numaraları toplamı, ilgili hacim fonksiyonu için başarı derecesi olarak değerlendirilmiştir. Bu durumda en küçük toplam sıra numarasına sahip fonksiyonun en başarılı hacim fonksiyonu olacağ1 öngörülmüştür.

İkinci aşamada, öncelikle oluşturulan rank tablosunda toplam hata yüzdesi \%1'den, mutlak hata yüzdesi de \%10'dan büyük modeller elenerek kalan modeller arasında tekrar bir değerlendirme yapılmıştır. Bu kez ölçüt olarak Ortalama Ayrılış (\%OA) (Chapman ve Meyer, 1949; Spurr, 1952; Alemdağ, 1962) kullanılmıştır (Denklem 2.13).

$$
\% \mathrm{OA}=\left\{\frac{1}{n} * \sum_{i=1}^{n}\left(\frac{\left|V_{i}-\widehat{V}_{l}\right|}{V_{i}}\right)\right\} * 100
$$

Burada; $\widehat{V}_{l}$ : denklem ile tahmin edilen $i$. ağaç hacmini, $V_{i}$ : ölçülen $i$. ağaç hacmini, $n$ : örnek ağaç adedini ifade etmektedir.

Öncelikli olarak değerlendirilen \%OA ölçütü yanında, regresyon modellerinin genel olarak çoklu doğrusal regresyon analizi varsayımlarına uygunlukları (normallik, sıfır ortalama, kovaryans matrislerinin eşitliği, doğrusallık, çoklu doğrusal bağıntı varsayımları, artıkların bağımsızlığı ve otokorelasyon) grafik ve testlerle incelenmiştir. Ayrıca, tüm modellerde özellikle küçük değerli boy ve çap bağımsız değişkenleri ile göz ardı edilemeyecek ya da düzenlenemeyecek şekilde doğal kanuniyetlere uygun olmayan hacim değerleri üretenler kontrollerle tespit edilmişlerdir. En uygun modeller ilk aşamadaki modellerin puanları yanında tüm bu incelemeler ve değerlendirmeler sonucu seçilmiştir.

\subsubsection{Seçilen modellerin uygulanabilirlik testleri}

Geliştirilen kabuklu gövde hacim denklemlerinin İzmir OBM fıstıkçamı meşcereleri için kullanım- 
larının uygun olup olmadığ 1 , artık değerler için normallik ve homojenlik varsayımları test edildikten sonra "Eşleştirilmiş t Testi" kullanılarak belirlenmiştir. Test için, kontrol grubu ağaçlarının gerçek hacim değerleri ile model tahmin değerleri kullanılmıştır.

\section{Bulgular ve Tartışma}

İzmir OBM kapsamında yapılan çalışmada, çift ve tek girişli gövde hacim denklemlerinin belirlenmesi aşamalarında kullanılan istatistik analizler, doğrusal formlu modeller için regresyon katsayıları olarak ifade edilen regresyon parametreleri, bu katsayıların önemlilik düzeyleri, başarı ölçütlerine ait iki aşamalı puanlama döküm çizelgeleri, kimi artık analizi ile ilgili test çıktıları ve uygunluk testleri çizelgeler biçiminde hazırlanmıştır.

\section{1. Çift girişli DKGHT ilişkin bulgular}

Yapılan ön incelemede bazı denklemlerin kısmen eksi değerli, kısmen de çap ya da boy bağımsız değişkenleri artarken, giderek azalan hacim değerleri ürettikleri belirlenmiştir. İzmir OBM genel kullanımı için denenen 28, 32, 33, 35, 42, 46, 47, $53,71,72$ ve 73 numaralı bu denklemler başarısız kabul edilmişlerdir.

Değerlendirmeye katılan modellere ilişkin regresyon parametreleri, katsayıların önemlilik düzeyleri ve logaritmik denklemler için hesaplanan "Düzeltme Faktörü $(f)$ ”" değerleri Ek Tablo 4’te verilmiştir.

Tablo 3 İzmir OBM çift girişli gövde hacim denklemlerine ilişkin başarı ölçüt değerleri Table 3. Success criteria for İzmir RDF double-entry tree volume equations

\begin{tabular}{|c|c|c|c|c|c|c|c|c|c|c|c|c|c|}
\hline \multirow{2}{*}{$\begin{array}{c}\text { Model } \\
\text { No }\end{array}$} & \multicolumn{2}{|l|}{$\overline{\mathrm{D}}$} & \multicolumn{2}{|l|}{$|\overline{\mathrm{D}}|$} & \multicolumn{2}{|l|}{ SD } & \multicolumn{2}{|l|}{ PVE } & \multicolumn{2}{|l|}{$\mathrm{TH}$} & \multicolumn{2}{|l|}{$\mathrm{MH}$} & \multirow{2}{*}{ Puan } \\
\hline & $\left(\mathrm{m}^{3}\right)$ & $\mathrm{R}$ & $\left(\mathrm{m}^{3}\right)$ & $\mathrm{R}$ & $\left(\mathrm{m}^{3}\right)$ & $\mathrm{R}$ & $\%$ & $\mathrm{R}$ & $\%$ & $\mathrm{R}$ & $\%$ & $\mathrm{R}$ & \\
\hline $26^{*}$ & $<0,0000$ & 4 & 0,0795 & 7 & 0,1863 & 16 & 98,9797 & 16 & $-0,0011$ & 4 & 7,8724 & 7 & 54 \\
\hline $27 *$ & $<0,0000$ & 2 & 0,0795 & 6 & 0,1863 & 15 & 98,9797 & 15 & $<0,0000$ & 2 & 7,8718 & 6 & 46 \\
\hline 29 & $-0,0192$ & 23 & 0,0834 & 16 & 0,1805 & 9 & 99,0319 & 9 & $-1,9022$ & 23 & 8,2573 & 16 & 96 \\
\hline 30 & 0,0241 & 26 & 0,1070 & 24 & 0,1908 & 17 & 98,9133 & 18 & 2,3843 & 26 & 10,5920 & 24 & 135 \\
\hline 31 & $-0,0149$ & 20 & 0,0875 & 19 & 0,1791 & 7 & 99,0502 & 7 & $-1,4776$ & 20 & 8,6606 & 19 & 92 \\
\hline $34 *$ & 0,0001 & 5 & 0,0795 & 5 & 0,1863 & 14 & 98,9797 & 14 & 0,0070 & 5 & 7,8718 & 5 & 48 \\
\hline 36 & $-0,0638$ & 29 & 0,1142 & 26 & 0,2955 & 24 & 97,3130 & 24 & $-6,3174$ & 29 & 11,3105 & 26 & 158 \\
\hline 37 & $-0,0747$ & 31 & 0,1210 & 29 & 0,3285 & 27 & 96,6624 & 28 & $-7,4018$ & 31 & 11,9799 & 29 & 175 \\
\hline 38 & 0,0110 & 16 & 0,0811 & 12 & 0,1952 & 19 & 98,8766 & 19 & 1,0918 & 16 & 8,0283 & 12 & 94 \\
\hline 39 & $-0,0113$ & 17 & 0,0830 & 14 & 0,1764 & 4 & 99,0815 & 4 & $-1,1158$ & 17 & 8,2166 & 14 & 70 \\
\hline 40 & $-0,0199$ & 24 & 0,0859 & 17 & 0,1823 & 11 & 99,0114 & 11 & $-1,9729$ & 24 & 8,5071 & 17 & 104 \\
\hline 41 & $-0,0126$ & 18 & 0,0870 & 18 & 0,1794 & 8 & 99,0489 & 8 & $-1,2447$ & 18 & 8,6147 & 18 & 88 \\
\hline 43 & $-0,0192$ & 22 & 0,0834 & 15 & 0,1805 & 10 & 99,0319 & 10 & $-1,9022$ & 22 & 8,2573 & 15 & 94 \\
\hline 44 & 0,1292 & 33 & 0,1850 & 32 & 0,6580 & 32 & 86,7820 & 32 & 12,7945 & 33 & 18,3195 & 32 & 194 \\
\hline $45^{*}$ & $<0,0000$ & 1 & 0,0826 & 13 & 0,1786 & 5 & 99,0620 & 5 & $<0,0000$ & 1 & 8,1823 & 13 & 38 \\
\hline $48 *$ & 0,0089 & 14 & 0,0809 & 11 & 0,1754 & 1 & 99,0934 & 1 & 0,8779 & 14 & 8,0124 & 11 & 52 \\
\hline $49 *$ & 0,0051 & 8 & 0,0895 & 20 & 0,2219 & 21 & 98,5519 & 21 & 0,5099 & 8 & 8,8589 & 20 & 98 \\
\hline 50 & 0,2108 & 34 & 0,2929 & 35 & 1,1675 & 35 & 58,6213 & 35 & 20,8758 & 34 & 29,0109 & 35 & 208 \\
\hline 51 & 0,6419 & 38 & 0,7577 & 38 & 3,3426 & 38 & $-240,5928$ & 38 & 63,5740 & 38 & 75,0340 & 38 & 228 \\
\hline 52 & 0,0734 & 30 & 0,1376 & 31 & 0,4627 & 31 & 93,5483 & 31 & 7,2647 & 30 & 13,6302 & 31 & 184 \\
\hline $54 *$ & $-0,0002$ & 6 & 0,0795 & 8 & 0,1863 & 13 & 98,9797 & 13 & $-0,0225$ & 6 & 7,8765 & 8 & 54 \\
\hline 55 & $-0,0271$ & 27 & 0,0808 & 10 & 0,1956 & 20 & 98,8538 & 20 & $-2,6831$ & 27 & 8,0062 & 10 & 114 \\
\hline 56 & 0,0480 & 28 & 0,1055 & 22 & 0,3126 & 26 & 97,0599 & 26 & 4,7523 & 28 & 10,4440 & 22 & 152 \\
\hline $57 *$ & $-0,0057$ & 9 & 0,0749 & 1 & 0,1791 & 6 & 99,0561 & 6 & $-0,5660$ & 9 & 7,4189 & 1 & 32 \\
\hline 58 & 0,0080 & 12 & 0,1184 & 28 & 0,3356 & 28 & 96,6881 & 27 & 0,7895 & 12 & 11,7226 & 28 & 135 \\
\hline 59 & 0,0084 & 13 & 0,1181 & 27 & 0,3454 & 30 & 96,4910 & 30 & 0,8281 & 13 & 11,6992 & 27 & 140 \\
\hline 60 & 0,0141 & 19 & 0,0897 & 21 & 0,2345 & 22 & 98,3777 & 22 & 1,3937 & 19 & 8,8850 & 21 & 124 \\
\hline 61 & 0,0190 & 21 & 0,1128 & 25 & 0,3424 & 29 & 96,5427 & 29 & 1,8831 & 21 & 11,1666 & 25 & 150 \\
\hline 62 & 0,2156 & 35 & 0,2829 & 34 & 1,0772 & 34 & 64,5181 & 34 & 21,3545 & 35 & 28,0152 & 34 & 206 \\
\hline 63 & 0,5229 & 37 & 0,6370 & 37 & 2,6860 & 37 & $-120,1382$ & 37 & 51,7813 & 37 & 63,0823 & 37 & 222 \\
\hline 64 & 0,2945 & 36 & 0,4057 & 36 & 1,7743 & 36 & 4,9062 & 36 & 29,1643 & 36 & 40,1799 & 36 & 216 \\
\hline 65 & 0,0948 & 32 & 0,2007 & 33 & 0,7618 & 33 & 82,6775 & 33 & 9,3836 & 32 & 19,8785 & 33 & 196 \\
\hline 66 & 0,0230 & 25 & 0,1060 & 23 & 0,3068 & 25 & 97,2173 & 25 & 2,2807 & 25 & 10,4973 & 23 & 146 \\
\hline $67 *$ & $<0,0000$ & 3 & 0,0786 & 2 & 0,1760 & 3 & 99,0896 & 3 & $<0,0000$ & 3 & 7,7888 & 2 & 16 \\
\hline 68 & 0,0110 & 15 & 0,0792 & 4 & 0,1833 & 12 & 99,0093 & 12 & 1,0846 & 15 & 7,8450 & 4 & 62 \\
\hline $69 *$ & -0.0078 & 11 & 0.0796 & 9 & 0.1757 & 2 & 99.0910 & 2 & -0.7734 & 11 & 7.8808 & 9 & 44 \\
\hline 70 & $-0,0059$ & 10 & 0,1236 & 30 & 0,2737 & 23 & 97,7964 & 23 & $-0,5886$ & 10 & 12,2443 & 30 & 126 \\
\hline $75 *$ & $-0,0044$ & 7 & 0,0789 & 3 & 0,1909 & 18 & 98,9282 & 17 & $-0,4402$ & 7 & 7,8139 & 3 & 55 \\
\hline
\end{tabular}

Tablo başlı̆̆ındaki $\overline{\mathrm{D}}$ : Ortalama Hata, $|\overline{\mathrm{D}}|$ : Ortalama Mutlak Hata, SD: Hataların Standart Sapması, \%PVE: Açılanan Varyans Yüzdesi, \%TH: Toplam Hata Yüzdesi, \%MH: Ortalama Mutlak Hata Yüzdesi, R: İstatistik modellerin her bir başarı ölçütü için aldıkları puan (Rank) ve *: İlk aşamada başarılı sayılan modelleri ifade eder. 
Non-linear modeller için anlamlılık değerleri hesaplanmamıştır.

İlk aşamada, en uygun regresyon denkleminin seçiminde kullanılan altı farklı ölçüt değerleri hesaplanarak elde edilen sonuçlar ile Tablo 3 düzenlenmiştir.

İkinci aşamada değerlendirilen ortalama ayrılış ölçütü ve bazı istatistikleri ile Tablo 4 oluşturulmuştur. Birinci aşamadaki puanlama yöntemi ile tekrar değerlendirilen modellerin yeni puanları, çizelgenin 1. Aşama Yeni Puanı sütununda yer almaktadır. Tablo 4'te, ilk aşamada başarılı olmuş, yeni puanları ile de ilk iki sırada yer alan model 67 ve model 45 'in baz1 hacimleri $\% 441$ ve $\% 617$ gibi yüksek bir hata oraniyla tahmin ettikleri görülmektedir. Numaraları 57 ile 75 olan modeller dışındaki tüm modellerin (yazı tipi rengi gri olan modeller) \%8'den daha fazla ortalama ayrılış yüzdesi değerine sahip oldukları gözlenmektedir.

Tablo 4 İzmir OBM çift girişli gövde hacim denklemlerine ilişkin \%OA ölçütü ile ilgili bazı istatistikler Table 4. Some statistics of \% OA criterion for Izmir RDF double-entry tree volume equations

\begin{tabular}{|c|c|c|c|c|c|c|c|c|c|}
\hline $\begin{array}{l}\text { Model } \\
\text { No }\end{array}$ & $\% \mathrm{OA}$ & $\begin{array}{c}\text { Standart } \\
\text { Hata }\end{array}$ & $\begin{array}{l}\text { Standart } \\
\text { Sapma }\end{array}$ & Aralık & Min. & Max. & Toplam & Adet & $\begin{array}{l}\text { 1. Aşama Yeni } \\
\text { Puanı }\end{array}$ \\
\hline 26 & 12,900 & 0,751 & 11,415 & 75,246 & 0,207 & 75,453 & 2979,835 & 231 & 42 \\
\hline 27 & 12,885 & 0,750 & 11,393 & 75,112 & 0,209 & 75,321 & 2976,376 & 231 & 34 \\
\hline 34 & 12,890 & 0,751 & 11,414 & 75,214 & 0,230 & 75,444 & 2977,688 & 231 & 36 \\
\hline 45 & 25,070 & 3,662 & 55,663 & 617,737 & 0,060 & 617,797 & 5791,134 & 231 & 32 \\
\hline 48 & 13,961 & 0,705 & 10,708 & 63,542 & 0,053 & 63,596 & 3224,943 & 231 & 42 \\
\hline 54 & 12,972 & 0,754 & 11,461 & 75,478 & 0,141 & 75,619 & 2996,545 & 231 & 42 \\
\hline $57 * *$ & 7,547 & 0,444 & 6,745 & 45,043 & 0,002 & 45,045 & 1743,465 & 231 & 28 \\
\hline 67 & 19,119 & 2,582 & 39,249 & 441,179 & 0,019 & 441,198 & 4416,426 & 231 & 16 \\
\hline 68 & 12,171 & 0,762 & 11,580 & 74,366 & 0,003 & 74,368 & 2811,516 & 231 & 42 \\
\hline 69 & 14,321 & 0,657 & 9,983 & 62,190 & 0,137 & 62,328 & 3308,215 & 231 & 40 \\
\hline $75 * *$ & 7,551 & 0,469 & 7,125 & 63,828 & 0,058 & 63,886 & 1744,388 & 231 & 42 \\
\hline
\end{tabular}

** İkinci aşamada başarılı sayılan modeller

Model 57 her ne kadar birinci aşamadaki puanı ve ortalama ayrılış yüzdesi değeriyle Model 75'ten öncelikli görünse de, küçük değerli çap ve boy değişkenleri için doğal kanuniyetlere aykırı hacim değerleri üretmektedir. Bu durumda tüm inceleme ve değerlendirmeler sonucu 75 numaralı modelin en uygun Fıstıkçamı Çift Girişli Gövde Hacim denklemi olarak seçilmesine karar verilmiştir.

Model 75 için regresyon katsayılarının tamamı $p<0,001$ önem düzeyinde sıfırdan farklı bulun- muştur. Modele ilişkin F değeri 22.326,522 olarak hesaplanmış ve elde edilen hacim denkleminin $p<0,001$ önem düzeyinde $(p=3,79 \mathrm{E}-280)$ verilere uygun olduğu sonucuna varılmıştır. Denklemin belirtme katsayısı $\left(\mathrm{R}^{2}\right)$ 0,997 olarak hesaplanmıştır. Buna göre, en uygun çift girişli gövde hacim modeli için $\overline{\mathrm{D}},|\overline{\mathrm{D}}|, \mathrm{SD}, \% \mathrm{PVE}, \% \mathrm{TH}, \% \mathrm{MH}$ ve \%OA ölçüt değerleri sırasılyla $-0,0044 \mathrm{~m}^{3} ; 0,0789$ $\mathrm{m}^{3} ; 0,1909 \mathrm{~m}^{3} ; \% 98,93 ; \%-0,4402 ; \% 7,8139$ ve \%7,551'dir. Denklem grafiği Şekil 2'de verilmiştir.

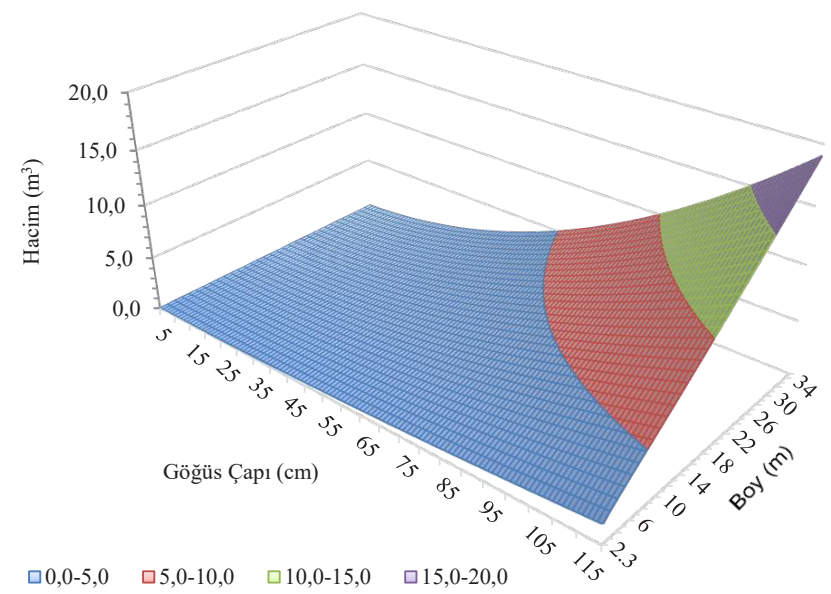

Şekil 2. İzmir OBM fıstıkçamı çift girişli gövde hacim denklemi (Model 75) grafiği Figure 2. Izmir RDF stone pine double-entry tree volume equation (Model 75) graph 
Seçilen hacim denkleminin kullanılabilirliği kontrol grubu verileri ile test edilmiştir. KolmogorovSmirnov ve Shapiro-Wilk normallik testlerinde farkların normal dağılıma sahip olduğu $(p=0,200$; $p=0,651)$ ve Levene testi ile de varyanslarının homojen olduğu $(p=0,824)$ belirlenmiştir. Bu durumda uygunluk denetimi için "Eşleştirilmiş t-Testi" yapılmış $p=0,678$ olarak hesaplanmıştır. $\mathrm{Bu}$ sonuçlar $(p>0,05)$ elde edilen çift girişli gövde hacim denkleminin \%95 güvenle kullanılabilir olduğunu göstermektedir (Tablo 5).

Tablo 5. "Model 75" için uygulanabilirlik kontrol grubu değerleri

Table 5. Applicability control group values for "Model 75"

\begin{tabular}{lrrrrrr}
\hline Normallik Testleri \\
\hline \multicolumn{3}{l}{ Kolmogorov-Smirnov ${ }^{\mathrm{a}}$} & \multicolumn{3}{c}{ Shapiro-Wilk } \\
\cline { 2 - 7 } & Statistic & df & Sig. & Statistic & df & Sig. \\
\hline fark &, 107 & 44 &, $200^{*}$ &, 980 & 44 &, 651 \\
\hline
\end{tabular}

*. This is a lower bound of the true significance.

a. Lilliefors Significance Correction

Varyansların Homojenliği Testi

\begin{tabular}{|c|c|c|c|c|c|c|c|}
\hline \multicolumn{3}{|c|}{ Levene Statistic } & df1 & & $\mathrm{df} 2$ & & Sig. \\
\hline & \multicolumn{2}{|c|}{, 050} & & 1 & & 86 &, 824 \\
\hline \multicolumn{8}{|c|}{ Eşleştirilmiş t-Testi } \\
\hline & \multicolumn{5}{|c|}{ Paired Differences } & \multirow[t]{3}{*}{$\mathrm{t}$} & \multirow[t]{3}{*}{ df Sig } \\
\hline & $\overline{\text { Mean }}$ & SD & $\mathrm{SE}$ & $95 \%$ & & & \\
\hline & & & Mean & \multicolumn{2}{|c|}{ Lower Upper } & & \\
\hline 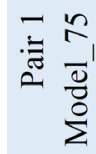 & 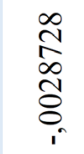 & 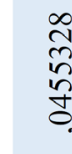 & \begin{tabular}{l}
0 \\
\multirow{8}{0}{} \\
$\infty$ \\
0 \\
8 \\
0
\end{tabular} & $\begin{array}{l}8 \\
\frac{8}{6} \\
\vdots \\
0 \\
1\end{array}$ & 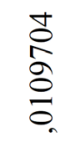 & $\frac{9}{\nabla_{n}}$ & 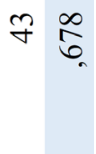 \\
\hline
\end{tabular}

\subsection{Tek girişli DKGHT ilişkin bulgular}

Yapılan ön incelemede bazı denklemler kısmen eksi değerli, kısmen de çap değeri artarken, giderek azalan hacim değerleri ürettikleri için başarısız kabul edilmiş ve yarıştırılmamıştır.

Değerlendirmeler sonucunda Model 10 en uygun Fıstıkçamı Tek Girişli Gövde Hacim denklemi olarak seçilmiştir. Hacim denklemindeki regresyon katsayılarının bir tanesi $\left(\beta_{2}\right) p<0,05$ önem düzeyinde, diğerleri ise $p<0,001$ önem düzeyinde sıfırdan farklı bulunmuştur. Bu modele ilişkin F değeri $6.169,505$ olarak hesaplanmış ve elde edilen hacim denkleminin $p<0,001$ önem düzeyinde $(p=3,47$ E-217) verilere uygun olduğu sonucuna varılmıştır. Bu denklemin belirtme katsay1sı $\left(R^{2}\right)$ 0,988, standart hatas1 (SD) ise 0,08139054 olarak hesaplanmıştır. En uygun tek girişli gövde hacim modelinin $\overline{\mathrm{D}},|\overline{\mathrm{D}}|, \mathrm{SD}, \% \mathrm{PVE}, \% \mathrm{TH}, \% \mathrm{MH}$ ve \%OA ölçütlerine göre verdiği sonuçlar sırasıyla $0,0110 \mathrm{~m}^{3} ; 0,1357$ $\mathrm{m}^{3} ; 0,3455 \mathrm{~m}^{3} ; \% 96,4984 ; \% 1,0862 ; \% 13,4423$ ve $\% 15,198$ 'dir.

Shapiro-Wilk ve Levene testlerinde, farkların normal dağılıma sahip $(p=0,126)$ ve varyanslarının homojen olduğu $(p=0,775)$ belirlenmiştir. Uygunluk denetimi için "Eşleştirilmiş t-Testi" yapılmış ve $p=0,985$ olarak hesaplanmıştır. $\mathrm{Bu}$ sonuçlar $(p>0,05)$ elde edilen tek girişli gövde hacim denkleminin \%95 güvenle kullanılabilir olduğunu göstermektedir.

\subsection{Karşılaştırmalar}

İzmir OBM için en uygun seçilen çift ve tek girişli modellerin tahminleri, fıstıkçamı için hazırlanmış diğer bazı hacim değerleri ile grafik ve tablo biçiminde karşılaştırılmıştır.

\subsection{1. Çift girişli hacim tabloları için karşılaştırılmalar}

İzmir OBM için geliştirilen fıstıkçamı çift girişli hacim denklemi, ülkemizde Antalya fıstıkçamı ağaçlandırma sahaları için geliştirilen (Güler, 2010) hacim denklemi yanında, İspanya (Millan ve ark., 1993), Portekiz (Correia ve ark., 2010) ve İtalya (Cutini ve ark., 2013) gibi farklı ülkelerde yapılmış çalışmalar sonucu düzenlenmiş fistıkçamı hacim denklemleri ile karşılaştırılmıştır.

Hacim değeri tahminleri farklı boy kademeleri için Şekil 3 ve Şekil 4'teki gibi düzenlenmiştir. Şekil 3 'te görüldüğü üzere, $25 \mathrm{~cm}$ gögüs çapına kadar, $5 \mathrm{~m}, 10 \mathrm{~m}$ ve $15 \mathrm{~m}$ boy gruplarında Antalya modeli yüksek, diğer model çıktısı hacimler ise hemen hemen yakın değerlerde seyretmektedir. Göğüs çapının 27-32 cm, boyun 15 m olduğu kısımda Antalya modelinin en yüksek, Portekiz modelinin en düşük, İzmir OBM modelinin Portekiz'den sonra ikinci sırada düşük, diğer iki modelin de (İtalya-İspanya) yakın hacim değerleri ürettiği gözlenmektedir. Şekil 4'te ise, $15 \mathrm{~m}$ ile $20 \mathrm{~m}$ boy gruplarında 49 $\mathrm{cm}$ göğüs çapına kadar İtalya, İspanya, İzmir OBM ve Portekiz modelleri en yüksekten düşüğe hacim değerleri ile sıralanmaktadır. Çapın 50 cm'den büyük olduğu $25 \mathrm{~m}$ boy grubunda ise en yüksek hacmi sırası ile İtalya, birbiri ile eşit sayılabilecek İspanya ile İzmir OBM ve Portekiz modellerinin ürettiği grafikte okunmaktadır. İspanya ve İzmir OBM değerlerinin birbirlerine oldukça yakın oldukları söylenebilir.

\subsubsection{Tek girişli hacim tabloları için karşılaştırılmalar}

Çalışmada elde edilen model çıktıları (i), Antalya Fıstıkçamı Ağaçlandırma Alanları için düzenlenen (Güler, 2010) değerler (ii), İzmir OBM, Bergama 


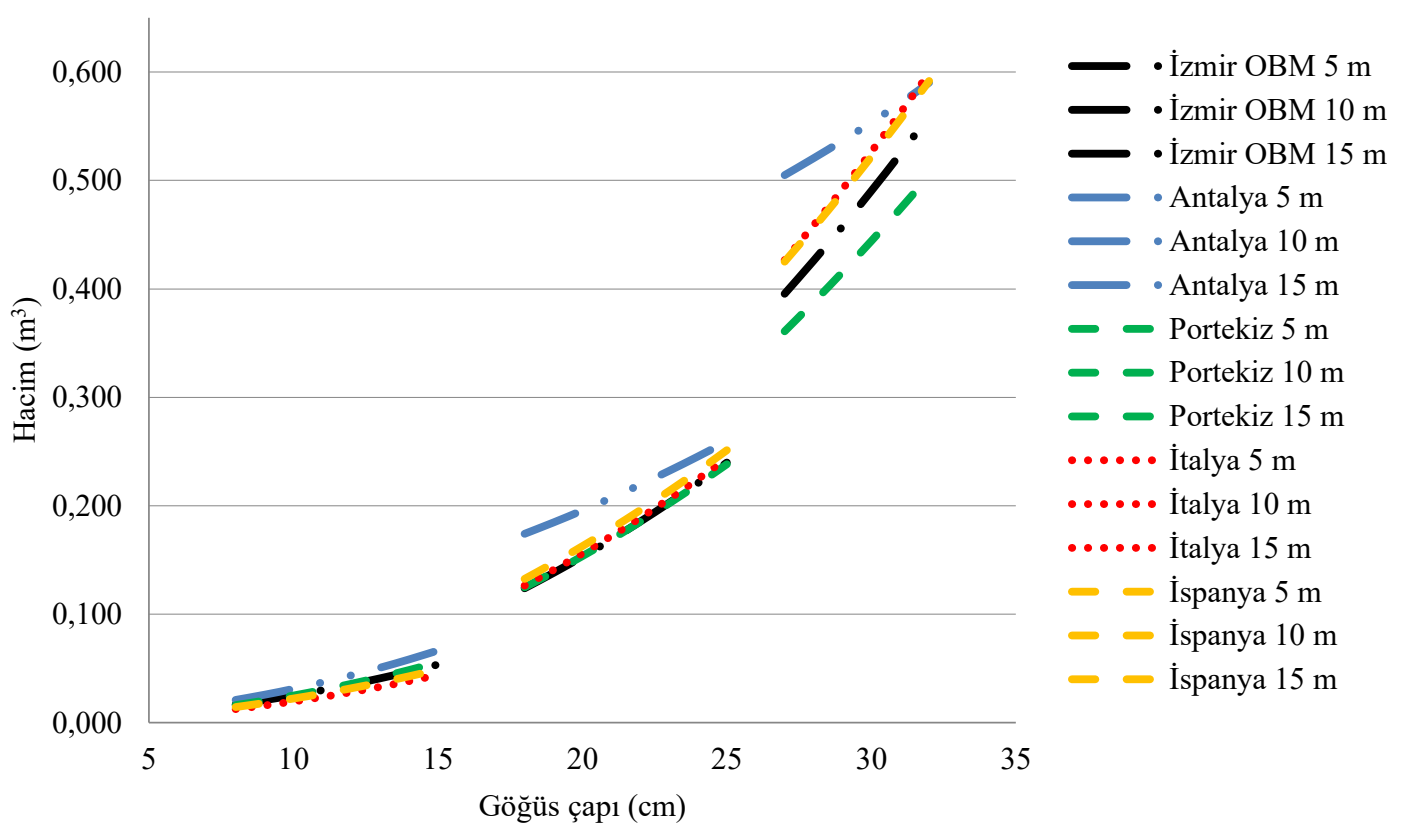

Şekil 3. Bazı çift girişli hacim denklemlerinin $5 \mathrm{~m}, 10 \mathrm{~m}$ ve $15 \mathrm{~m}$ boylarda karşılaştırılmaları grafiği Figure 3. Comparison graph of some double-entry volume equations at $5 \mathrm{~m}, 10 \mathrm{~m}$ and $15 \mathrm{~m}$ lengths

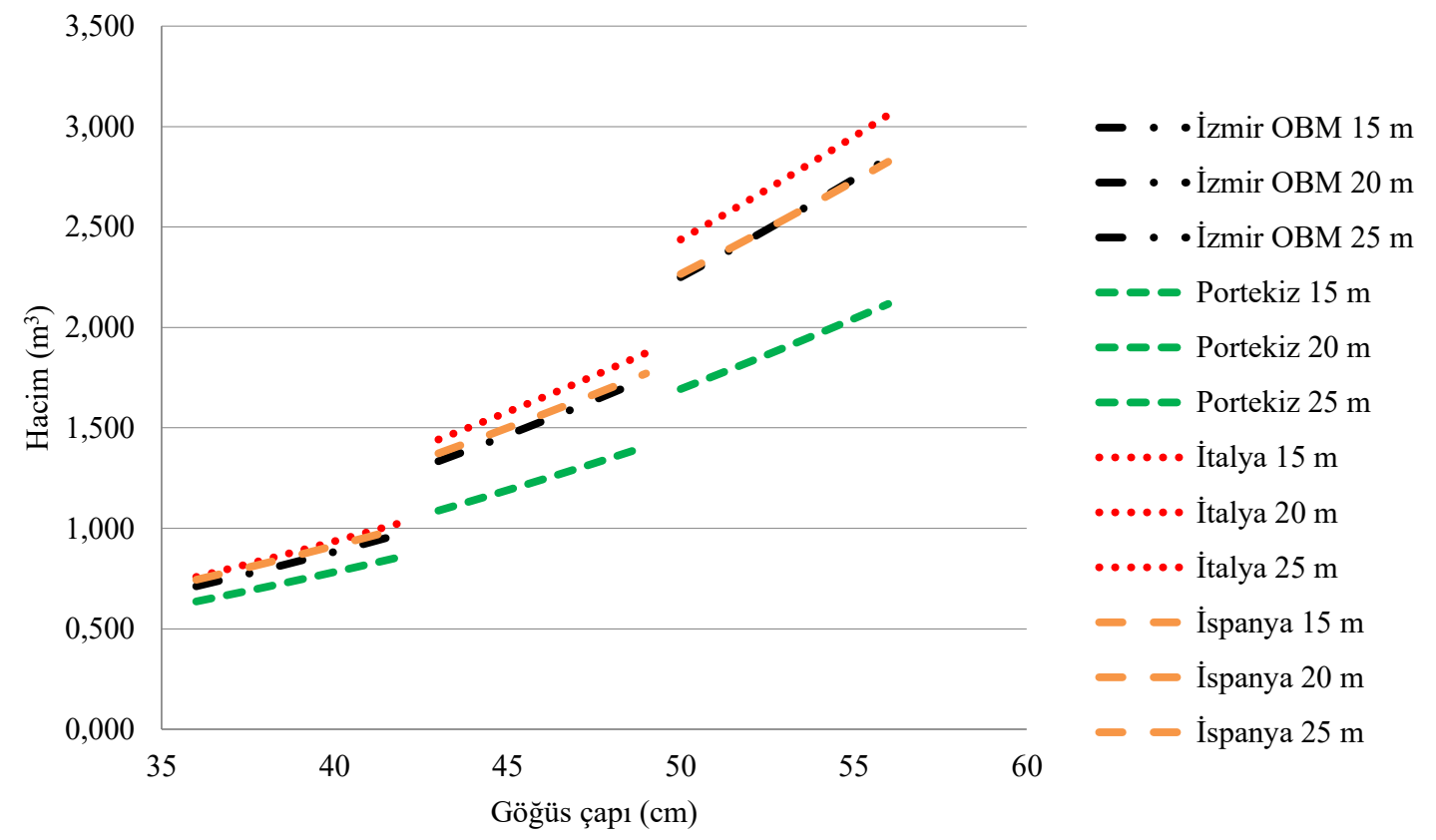

Şekil 4. Bazı çift girişli hacim denklemlerinin $15 \mathrm{~m}, 20 \mathrm{~m}$ ve $25 \mathrm{~m}$ boylarda karşılaştırılmaları grafiği Figure 4. Comparison graph of some double-entry volume equations at $15 \mathrm{~m}, 20 \mathrm{~m}$ and $25 \mathrm{~m}$ lengths

Orman İșletme Müdürlüğü, Kozak Orman İșletme Şefliği’ne ait orman amenajman planında yer alan fıstıkçamı tek girişli gövde hacim tablolarındaki değerler (iii) ve İtalya'da dört kıyı şeridinden alınan toplam 184 adet örnek fistıkçamı verileri kullanılarak düzenlenmiş (Cutini ve ark., 2013) model değerleri (iv) ile Tablo 6'da karşılaştırılmıştır.
İzmir OBM değerleri ile Kozak İșletme Şefliği Amenajman Planı hacim değerleri karşılaştırıldığında, genel olarak ve özellikle kalın çaplarda hacimlerin plan tablosunda çok daha düşük tahmin edildiği gözlenmektedir. İtalya değerleri ise her çap kademesi için karşılaştırılan diğer hacim değerlerinden daha yüksektir. 
Tablo 6. Bazı fıstıkçamı tek girişli gövde hacim modellerine ilişkin değerlerin karşılaştırılması Table 6. Comparison of values for some stone pine single entry stem volume models

\begin{tabular}{|c|c|c|c|c|c|}
\hline \multirow[b]{2}{*}{$\begin{array}{c}\text { Çap } \\
\text { kademeleri } \\
\quad(\mathrm{cm})\end{array}$} & \multirow[b]{2}{*}{$\begin{array}{c}\text { Çap kademeleri } \\
\text { ortas1 } \\
(\mathrm{cm})\end{array}$} & \multicolumn{4}{|c|}{$\operatorname{Hacim}\left(\mathrm{m}^{3}\right)$} \\
\hline & & $\begin{array}{c}\text { Kozak Orman } \\
\text { Isşletme Şefliği } \\
\text { Amenajman Planı } \\
\text { değerleri }\end{array}$ & $\begin{array}{l}\text { İzmir OBM için } \\
\text { düzenlenen model } \\
\text { tahmin değerleri }\end{array}$ & $\begin{array}{l}\text { Antalya F1stık- } \\
\text { çamı Ăg. Al. için } \\
\text { düzenlenen model } \\
\text { tahmin değerleri } \\
\text { (Güler, 2010) }\end{array}$ & $\begin{array}{l}\text { İtalya'da bir çalış- } \\
\text { mada (Cutini ve } \\
\text { ark., 2013) dü- } \\
\text { zenlenmiş model } \\
\text { tahmin değerleri }\end{array}$ \\
\hline $8-11,9$ & 10 & 0,010 & 0,025 & 0,034 & 0,077 \\
\hline $12-15,9$ & 14 & 0,030 & 0,054 & 0,068 & 0,151 \\
\hline $16-19,9$ & 18 & 0,080 & 0,103 & 0,113 & 0,249 \\
\hline $20-23,9$ & 22 & 0,140 & 0,174 & 0,169 & 0,373 \\
\hline $24-27,9$ & 26 & 0,220 & 0,271 & 0,236 & 0,521 \\
\hline $28-31,9$ & 30 & 0,340 & 0,399 & 0,315 & 0,693 \\
\hline $32-35,9$ & 34 & 0,430 & 0,559 & 0,417 & 0,890 \\
\hline $36-39,9$ & 38 & 0,650 & 0,755 & - & 1,112 \\
\hline $40-43,9$ & 42 & 0,860 & 0,990 & - & 1,358 \\
\hline $44-47,9$ & 46 & 1,140 & 1,265 & - & 1,629 \\
\hline $48-51,9$ & 50 & 1,461 & 1,582 & - & 1,925 \\
\hline $52-55,9$ & 54 & 1,840 & 1,943 & - & 2,245 \\
\hline $56-59,9$ & 58 & 2,260 & 2,349 & - & 2,590 \\
\hline $60-63,9$ & 62 & 2,700 & 2,802 & - & 2,960 \\
\hline $64-67,9$ & 66 & 3,150 & 3,302 & - & - \\
\hline $68-71,9$ & 70 & 3,470 & 3,850 & - & - \\
\hline $72-75,9$ & 74 & 3,790 & 4,447 & - & - \\
\hline $76-79,9$ & 78 & 4,180 & 5,094 & - & - \\
\hline $80-83,9$ & 82 & 4,500 & 5,790 & - & - \\
\hline $84-87,9$ & 86 & 4,820 & 6,535 & - & - \\
\hline $88-91,9$ & 90 & 5,140 & 7,331 & - & - \\
\hline $92-95,9$ & 94 & 5,460 & 8,176 & - & - \\
\hline $96-99,9$ & 98 & 5,780 & 9,072 & - & - \\
\hline $100-103,9$ & 102 & 6,100 & 10,017 & - & - \\
\hline $104-107,9$ & 106 & 6,420 & 11,011 & - & - \\
\hline
\end{tabular}

\section{Sonuç ve Öneriler}

\subsection{Sonuç}

Bu çalışmada İzmir Orman Bölge Müdürlüğü s1nırları içerisinde yer alan fıstıkçamı meşcerelerinde kullanılabilecek kabuklu gövde hacim değerleri tahminleri için tek ve çift girişli gövde hacim denklemleri geliştirilmiştir. Toplam 275 adet örnek ağaçtan elde edilen veriler Regresyon analizi yöntemi ile değerlendirilmiştir. İstatistik modeller arasindan en uygun olanları Ortalama Hata, Ortalama Mutlak Hata, Hataların Standart Sapması, Açıklanan Varyans Yüzdesi, Toplam Hata Yüzdesi, Ortalama Mutlak Hata Yüzdesi ve Ortalama Ayrılış Yüzdesi başarı ölçütleri ile seçilmiştir.

Değerlendirmeler sonucu en uygun seçilen denklemler Tablo 7'de verilmiştir. Fıstıkçamı ağaç türü için çift girişli hacim tahmin değerleri Ek Tablo 5a, b, c'de; tek girişli tahmin değerleri ise Ek Tablo 6'da sunulmuştur.

Tablo 7. İzmir OBM için en uygun seçilen çift ve tek girişli gövde hacim denklemleri Table 7. Double and single-entry tree volume equations selected best for Izmir RDF

- $\quad$ Cift Girișli DKGH denklemi

$$
V=1,0049076 * 10\left(-4,6348411+1,0350721 * \log \left(d^{2} h\right)+15,8686932 *\left(\frac{1}{h+6}\right)^{2}+5,4137226 *\left(\frac{1}{d * h}\right)\right)
$$

- Tek girişli DKGH denklemi

$$
V=1,0177162 * 10^{\left(-5,450945+3,388001 * \log d-0,025049 *(\log d)^{4}+4,755827 *\left(\frac{1}{d}\right)\right)}
$$


Denklemlerin uygunluk denetimleri gerekli varsayımların kontrolü ve devamla "Eşleştirilmiş tTesti” ile 44 adet örnek ağaçtan oluşan bağımsız bir veri grubu kullanılarak yapılmıştır. İzmir OBM kapsamında her iki denklemin, fıstıkçamı ağaç türü için \%95 güvenle kullanılabilir olduğu sonucuna varılmıştır.

\section{2. Öneriler}

Araştırma sürecinde karşılaşılan problemler doğrultusunda, yapılacak benzer çalışmalarda araştırmacılara yardımcı olabileceği düşünülen yöntemlere ve çalışma sonucunun uygulamada kullanımına ilişkin bazı önerilerde bulunulmuştur.

- Çalışmada, örnek ağaç hacimlerinin hesaplanmasında “Smalian Hacim Formülü” kullanılmıştır. Seksiyon uzunluğunun $1 \mathrm{~m}$ olarak seçilmesi genel olarak uygun olsa da, genç örnek ağaçlar için $1 \mathrm{~m}$ büyük bir değerdir. Genç örnek ağaçlarin hacimleri az sayıda seksiyon verisi ile fazla hesaplanmaktadır. $\mathrm{Bu}$ nedenle, yeni yapılacak gövde hacim denklemleri düzenlenmesi çalışmalarında ince çaplı örnek ağaçlarda yapılacak ölçüler için seksiyon uzunluğunun 1 metreden daha küçük tutulması önerilir. Genel özellikleri ile bu ağaçları gögüs çapları $8 \mathrm{~cm}$ 'den ve boyları da 3 m'den küçük fertler şeklinde tanımlamak mümkün olsa da, konu ile ilgili bir çalışma bulunmaması sonucu hangi fertlerde seksiyon uzunluğunun kaç olacağına dair bir rakam vermek pek mümkün değildir. Yine de bu kapsamda bir çalışma yapılana kadar, seksiyon uzunluklarının gövde üzerinde en az 5 ölçme yapılacak şekilde ayarlanmasının uygun olacağı düşünülmektedir.

- Örnek ağaç niteliği taşıyan ve ölçü işlemlerinin hassas yapılabilmesi için kesilerek ölçülmesi gereken ağaçların teminindeki güçlükler, uygulamada kaybedilen zamanla birlikte ciddi şekilde sorun olabilmektedir. Bu gibi problemlerin yaşanabileceği öngörülen çalışmalar için mümkünse veri türetme olanağının olduğu gövde analizi yöntemi tercih edilebilir. Ancak çoklu doğrusal regresyon denkleminin yorumlanması bağımsız değişkenlerin kuvvetli bir şekilde ilişkili olmaması varsayımına bağlıdır. Gövde analizinde tek ağaçtan türetilecek örnek ağaç verileri birbiri ile sıkı biçimde ilişkilidir ve bu varsayımı bozabileceği unutulmamalıdır.

- Ortalama Hata, Ortalama Mutlak Hata, Hataların Standart Sapması, Açıklanan Varyans Yüzdesi, Toplam Hata Yüzdesi ve Ortalama Mutlak Hata
Yüzdesinden oluşturulan başarı ölçüt seti gövde hacim modeli düzenlenmesi çalışmalarında sıkça kullanılmaktadır. Ortalama hata ile ortalama hata yüzdesi, ortalama mutlak hata ile ortalama mutlak hata yüzdesi ve çoğunlukla hataların standart sapması ile açıklanan varyans yüzdesi ölçüt ikilileri her bir model için aynı sıralamayı, yani eşit puanı vermektedir. Model sayısının fazla olduğu durumlarda sıralama oluşturulduktan sonra bile, ilk ona giren modeller tekrar kendi aralarında puanlandıklarında sıralamanın tutars1z bir biçimde değişebildiği de gözlenmiştir. En uygun modelin objektif biçimde seçilebilmesi için; regresyon varsayımlarını da içeren güçlü ve sağlam bir algoritma oluşturulması, doğal kanuniyetler şeklinde ifade edilen özelliklerin tanımlanmaları ile her birinin matematik ve istatistik olarak ifade edilmeleri, bu ifadelerin de başarı ölçütleri olarak düzenlenmeleri ve karar verme yöntemlerinin geliştirilmesi gerektiği düşünülmektedir. Yöresel ve bölgesel hacim tablolarının gerekliliği ile ülkemizde gövde hacim tabloları düzenleme çalışmalarının devam edeceği de göz önüne alınarak, başarı ölçütlerinin seçimi ve kombinasyonlarının optimizasyonu ile ilgili çalışmalar yanında değerlendirme yöntemleri ile ilgili araştırmaların yapılmasının gerekli ve önemli olduğu söylenebilir.

- Türkiye'de, farklı ağaç türleri için düzenlenmiş birçok gövde hacim tablosu mevcuttur. Aynı ağaç türünün aynı çaplı bireyleri arasında bile, bonitet ve meşcere parametrelerine bağlı olarak hacim değeri farkl1lıklar gösterebilmektedir (Pehlivan, 2010). Aynı ağaca ait hacim tablolarının yetişme ortamı farklılıkları dikkate alınmadan geniş coğrafi bölgeler içerisinde kullanıldığı da genel olarak bilinmektedir. Bunun sonucu olarak gövde hacim tahminlerinde hataların ortaya çıkabildiği farklı çalışmalarla ortaya konmuştur (Özçelik, 2008; Brooks ve ark., 2008). Bu nedenlerle gövde hacim tablolarının yöresel veya bölgesel ölçeklerde düzenlenmelerinin ormanc1l1k uygulamaları için daha yararlı olacağı ifade edilebilir. Bununla birlikte, Muğla OBM sınırları içinde fıstıkçamı hacim tablosu değerlerinin sorunlu olduğu plan ünitelerinde, çalışmamıza ait çift girişli gövde hacim modellerinden türetilecek tek girişli tabloların kullanımının mümkün olabileceği düşünülmektedir. Ancak, öncelikle istatistiksel olarak uygunlukları test edilmelidir.

- İzmir OBM fıstıkçamı meşcerelerinde servetin gerçeğe en yakın bir şekilde belirlenebilmesi amaçlanmaktadır. Bu nedenle, yenilenecek or- 
man amenajman planlarında fistıkçamı ağaç türü için bu çalışmada düzenlenen modellerin kullanılmaları uygun olacaktır.

- İzmir OBM sınırları içerisinde yer alan ve fistıkçamı meşcerelerine sahip her bir plan ünitesi için tek girişli hacim ve artım tablolarının hazırlanması gerekmektedir. $\mathrm{Bu}$ tabloların, öncelikle bu çalışma sonucu geliștirilen çift girişli hacim denklemi üzerinden düzenlenmesi önerilmektedir. Ancak bunun mümkün olmadığ durumlarda hazırlanan tek girişli model tabloları kullanılabilir.

- Orman sayılmayan tapulu taşınmazlar üzerindeki fıstıkçamı ağaçlarının hacim değerlerinin belirlenmesi gerektiği durumlarda da üretilen modeller kullanılabilir.

\section{Teşekkür}

Bu çalışma, Orman Genel Müdürlüğü, Ege Ormancılık Araştırma Enstitüsü Müdürlügü 15.3306/20142016-2017-2018 numaralı projesi kapsamında yürütülmüştür. Çalışma sürecindeki yardımları için Dokuz Eylül Üniversitesi Fen Fakültesi İstatistik Bölümü öğretim üyesi Doç. Dr. Neslihan DEMÍREL'e, Isparta Uygulamalı Bilimler Üniversitesi Orman Fakültesi Orman Mühendisliği Bölümü öğretim üyeleri Prof. Dr. Serdar CARUS ve Prof. Dr. Yılmaz ÇATAL'a teşekkür ederiz.

\section{Kaynaklar}

Akalp, T., 1978. Türkiye'deki Doğu ladini (Picea orientalis Lk. Carr.) ormanlarında hasılat araştırmaları. Doktora Tezi, İstanbul Üniversitesi, Fen Bilimleri Enstitüsü, İstanbul.

Alemdağ, Ş., 1962. Türkiye'deki Kızılçam Ormanlar1nın Gelişimi, Hasılat ve Amenajman Esasları. Ormanc1lık Araştırma Enstitüsü, Teknik Bülten No: 11, Ankara.

Alemdağ, Ş., 1967. Türkiye'deki Sarıçam Ormanlarının Kuruluşu, Verim Gücü ve Bu Ormanların İşletilmesinde Takip Edilecek Esaslar, Ormancılık Araştırma Enstitüsü, Teknik Bülten No: 20, Ankara.

Asan, Ü., 1984. Kazdağı Göknarı (Abies equi-trojani Ashers, et Sinten.) Ormanlarının Hasılat ve Amenajman Esasları Üzerine Araştırmalar. İÜ Orman Fakültesi, İÜ Yayın No: 3205, OF Yayın No: 365, Taş Matbaası, İstanbul.

Bektaş, E., 2012. Fıstıkçamı (Pinus pinea L.) odun dışı ürün envanterinin yapılması ve hasılat bileşenleri yönünden irdelenmesi. Rapor, İzmir OBM, 17. Orman Amenajman Başmühendisliği. İzmir.

Bozkuş, H.F ve Carus, S., 1997. Toros göknarı (Abies clicica Carr.) ve sedir (Cedrus libani Link.)'in çift girişli gövde hacim tabloları ve mevcut tablolarla karşılaşt1- r1lması. İstanbul Üniversitesi Orman Fakültesi Dergisi 47(1): 51-70.

Brooks, J.R., Jiang, L., Özçelik, R., 2008. Compatible stem volume and taper equations for brutian pine, cedar of lebanon, and cilicica fir in Turkey. Forest Ecology and Management 256: 147-151.

Carus, S. ve Su, Y., 2014. Antalya-Korkuteli Yöresi Kızılçam ağaçlandırmaları için tek ve çift girişli ağaç hacim tablosunun düzenlenmesi ve mevcut tablolar ile k1yaslanması. II. Ulusal Akdeniz Orman ve Çevre Sempozyumu "Akdeniz Ormanlarının Geleceği: Sürdürülebilir Toplum ve Çevre”, 22-24 Ekim 2014, Isparta.

Chapman, H.H. ve Meyer, W.H., 1949. Forest Mensuration. McGraw-Hill Book Company, Inc., New York.

Correia, A.C., Tomé, M., Pacheco, C.A., Faias, S., Dias, A.C., Freire, J., Carvalho, P.O. and Pereira, J.S., 2010. Biomass allometry and carbon factors for a Mediterranean pine (Pinus pinea L.) in Portugal. Forest Systems 19(3): 418-433.

Cutini, A., Chianucci, F., Manetti, M.C., 2013. Allometric relationships for volume and biomass for stone pine (Pinus pinea L.) in Italian coastal stands. iForest 6: 331337.

Çatal, Y., Gürlevik, N., Karatepe, Y., Carus, S., 2005. Isparta-Gölcük Yöresi Yalancı Akasya (Robinia pseudoacacia L.) Meşcereleri İçin Tek ve Çift Girişli Ağaç Hacim Tablosu. Süleyman Demirel Üniversitesi Orman Fakültesi Dergisi A(2):78-90.

Doğu, D., Koç, K.H., As, N., Atik, C., Aksu, B., Erdinler, S., 2002. Türkiye'de yetişen endüstriyel öneme sahip ağaçların temel kimlik bilgileri ve kullanıma yönelik genel değerlendirme. İstanbul Üniversitesi Orman Fakültesi Dergisi B 51(2): 69-84.

Eler, Ü. 1986. Antalya Bölgesi fıstıkçamı ağaçlandırma alanlarında fistık ve odun verimi. Ormancılık Araştırma Enstitüsü Dergisi 63(1):113-121.

Eraslan, Ü., 1954. Trakya ve Bilhassa Demirköy Mıntıkası Meşe Ormanlarının Amenajman Esasları Hakkında Araştırmalar. OGM Yayını, Ankara.

Ercanl1, İ., Güvendi, E., Güney, D., Günlü, A., Altun, L., 2008. Sinop yöresi Sahilçam1 (Pinus pinaster Ait.) ağaçlandırmalarına ilişkin tek ve çift girişli ağaç hacim tablolarının düzenlenmesi. Kastamonu Üniversitesi Orman Fakültesi Dergisi 8(1): 14-25.

Erdemir, Ö., 1974. Sarıkamış, Göle ve Oltu Mıntıkaları Saf Sarıçam Meşcerelerinde Hasılat Araştırmaları. OAE Yayınlan, Teknik Büten. Seri No: 59.

Erkan, N., 1997. Elazığ ve çevresindeki karaçam (Pinus nigra Arnold.) ağaçlandırmaları için hacim tablosu. Güneydoğu Anadolu Ormancılık Araştırma Enstitüsü Dergisi 1(1):61-72.

Erkin, K., 1948. Seben mıntıkası Sarıçamları üzerinde 
hacim, şekil emsali ve genel olarak hasılat araştırmaları. Basılmamış doktora tezi.

Fady, B., Fineschi, S., Vendramin, G.G., 2004. Eufrogen Technical Guidelines for Genetic Conservationand Use for Italian Stone Pine (Pinus pinea L.). International Plant Genetic Reseurces Institute, Rome, Italy.

Firat, F., 1943. Fıstıkçamı ormanlarımızda meyve ve odun verimi bakımından araştırmalar ve bu ormanların amenajman esasları. Ankara Yüksek Ziraat Enstitüsü, Say1 141, Ankara.

Fırat, F., 1973. Dendrometri. İ.Ü. Orman Fakültesi Yayını, İ.Ü. Yayın No: 1800, O.F. Yayın No:193, Kutulmuş Matbaası, İstanbul.

Gülen, İ., 1959. Karaçam (Pinus nigra Arnold) hacim tablosu. İstanbul Üniversitesi Orman Fakültesi Dergisi Seri A, 9(1): 97-112.

Güler, S., 2010. Fıstıkçamı (Pinus pinea L.)'nın genel özellikleri ve Antalya Yöresi fıstıkçamı ağaçlandırma alanları için gövde hacim tablosu. Batı Akdeniz Ormancılık Araştırma Müdürlüğü Dergisi 10(2): 73-96.

Kahriman, A., Sönmez, T., Şahin, A., 2017. Antalya ve Mersin Yöresi kızılçam meşcereleri için ağaç hacim tabloları. Kastamonu Üniversitesi Orman Fakültesi Dergisi 17(1): 9-22.

Kalıpsız, A., 1962. Doğu Kayınında Artım Büyüme Araştırmaları. Teknik Bülten, OGM Yayını, Ankara.

Kalıpsız, A., 1984. Dendrometri. İÜ Orman Fakültesi, Yayın No: 3149/354, İstanbul.

Kılc1, M., Sayman, M., Akbin, G., 2000. Bat1 Anadolu'da Fıstıkçamı (Pinus pinea L.)'nın Gelişmesini Etkileyen Faktörler. Orman Bak. Yayın No: 115, İzmir Orman Toprak Laboratuvar Müdürlüğü Yayın No: 09, İzmir.

Kılc1, M., Akbin, G., Sayman, M., 2014. "Fıstıkçamı (Pinus pinea L.)'nın Yayılış Alanları”. Fıstıkçamı (Pinus pinea L.), Editörler: Kılc1, M., Akbin, G., Sayman, M., Ege Ormancılık Araştırma Enstitüsü Müdürlüğü, Çeşitli Yayınlar Serisi, İzmir.

Köhl, M., Magnussen, S., Marchetti, M., 2006. Sampling Methods, Remote Sensing and GIS Multiresource Forest Inventory. Springer, Berlin.

Loetsch, F., Zöhrer, F., Haller, K.E., 1973. Forest Inventory, Volume II. BLV Verlagsgesellschaft München Benn Wien, München.
Millan, J.M., Lazoro, P.A., Doncel, I.G., 1993. Ecuaciones alometricas de tres variables: estimacion del volumen, crecimiento. Porcentaje de Corteza de Las Principales Especies Maderables Esponolas. Invest. Agrar., Sist. Recur. For. 2(2): 211-226.

Miraboğlu, M., 1955. Göknarlarda Şekil ve Hacim Araştırmaları. O.G.M. Yayın No: 188, Seri No: 5, İstanbul.

OGM, 2019. Orman Genel Müdürlüğü, Ormancılık İstatistikleri.

Özçelik, R., 2008. Comparison of formulae for estimating tree bole volumes of Pinus sylvestris. Scandinavian Journal of Forest Research 23: 412-418.

Özçelik, R., 2010. Bucak yöresi kızılçam, sedir ve Toros göknarı türleri için hacim denklemleri. Süleyman Demirel Üniversitesi Orman Fakültesi Dergisi Seri A, 2: 1-15.

Pehlivan, S., 2010. Sarıçam (Pinus sylvestris L.) ağaç hacim tablolarının düzenlenmesi. Yüksek Lisans Tezi, KTÜ. Fen Bilimleri Enstitüsü, Trabzon.

Sakıcı, O.E. ve Yavuz, H., 2003. Ilgaz Dağı göknar meşcereleri için hacim fonksiyonları. Gazi Üniversitesi Orman Fakültesi Dergisi 3(2): 155-168.

Sakıc1. O.E., Sağlam, F., Seki, M., 2018. Kastamonu Orman Bölge Müdürlüğü karaçam meşcereleri için tek ve çift girişli ağaç hacim denklemleri. Turkish Journal of Forestry 19(1): 20-29.

Saraçoğlu, N., 1998. Kızılağaç (Alnus glutinosa Gaertn. subsp. barbata (C.A. Mey) Yalt.) gövde hacim tablosu. Turkish Journal of Agriculture and Forestry 22: 215225.

Spurr, S.H., 1952. Forest Inventory. The Ronald Press Company, Newyork.

Sun, O., Eren, M.E., Orpak, M., 1978. Temel ağaç türlerimizde tek ağaç ve birim alandaki odun çeşidi oranlarının saptanması. TÜBİTAK Tarım ve Ormancılık Araştırma Grubu Proje No:288, Ankara.

Yavuz, H., 1995. Taşköprü Orman İşletmesinde sarıçam ve karaçam için uyumlu gövde çapı, gövde hacmi ve hacim oran denklem sistemlerinin geliştirilmesi. Basılmamış Doçentlik Tezi, KTÜ. Orman Mühendisliği Bölümü, Orman Amenajmanı Anabilim Dalı, Trabzon.

Yavuz, H., 1999. Taşköprü Yöresinde karaçam için hacim fonksiyonlar1 ve hacim tablolar1. Turkish Journal of Agriculture and Forestry 23(5): 1181-1188. 
Ek Tablo 1. Test edilen tek girișli model formları Annex 1. Tested single-entry model forms

\begin{tabular}{ll}
\hline$V=\beta_{0}+\beta_{1} d^{2}+\varepsilon$ & $(01)$ \\
\hline$V=\beta_{0}+\beta_{1} d+\beta_{2} d^{2}+\varepsilon$ & $(02)$ \\
\hline$V=\beta_{1} d+\beta_{2} d^{2}+\varepsilon$ & $(03)$ \\
\hline $\log V=\beta_{0}+\beta_{l} \log d+\varepsilon$ & $(04)$ \\
\hline $\log V=\beta_{0}+\beta_{l} \log d+\beta_{2}(l / d)+\varepsilon$ & $(05)$ \\
\hline $\log V=\beta_{0}+\beta_{l}(\log d)+\beta_{2}(\log d)^{4}+\varepsilon$ & $(06)$ \\
\hline $\ln V=\beta_{0}+\beta_{l} \ln d+\varepsilon$ & $(07)$ \\
\hline $\ln V=\beta_{0}+\beta_{l} \ln d+\beta_{2}(l / d)+\varepsilon$ & $(08)$ \\
\hline $\ln V=\beta_{0}+\beta_{l} \ln d+\beta_{2}(\ln d)^{4}+\varepsilon$ & $(09)$ \\
\hline $\log V=\beta_{0}+\beta_{l} \log d+\beta_{2}(\log d)^{4}+\beta_{3}(1 / d)+\varepsilon$ & $(10)$ \\
\hline$V=\beta_{0}+d^{\beta_{1}}+\varepsilon$ & $(11)$ \\
\hline$V=\beta_{1}{ }^{*} d^{\beta_{2}}+\varepsilon$ & $(12)$ \\
\hline
\end{tabular}

\begin{tabular}{lc}
\hline$V=\beta_{0}+\beta_{1} d^{\beta_{2}}+\varepsilon$ & $(13)$ \\
\hline$V=\mathrm{e}^{\left(\beta_{0}+\beta_{1}\left(d /\left(\beta_{2}+d\right)\right)\right)}+\varepsilon$ & $(14)$ \\
\hline$V=\beta_{0}+\beta_{1} d+\beta_{2} d^{2}+\beta_{3}(l / d)+\varepsilon$ & $(15)$ \\
\hline $\ln V=\beta_{0}+\beta_{I}(\ln d)^{2}+\varepsilon$ & $(16)$ \\
\hline $\log V=\beta_{0}+\beta_{I}(\log d)^{2}+\varepsilon$ & $(17)$ \\
\hline $\ln V=\beta_{0}+\beta_{I}(\ln d)^{4}+\beta_{2}(1 / d)+\varepsilon$ & $(19)$ \\
\hline $\log V=\beta_{0}+\beta_{I}(\log d)^{4}+\beta_{2}(l / d)+\varepsilon$ & $(20)$ \\
\hline $\ln V=\beta_{0}+\beta_{I}(\ln d)^{2}+\beta_{2}(\ln d)^{4}+\varepsilon$ & $(21)$ \\
\hline $\log V=\beta_{0}+\beta_{I}(\log d)^{2}+\beta_{2}(\log d)^{4}+\varepsilon$ & $(22)$ \\
\hline$V^{(1 / 2)}=\beta_{0}+\beta_{1} d+\varepsilon$ & $(23)$ \\
\hline$V=\beta_{0}+\beta_{1} d+\beta_{2} d^{2}+\beta_{3} d^{3}+\varepsilon$ & $(24)$ \\
\hline$V=\beta_{0}+\beta_{1} d+\beta_{2} d^{2}+\beta_{3} d^{3}+\beta_{4} d^{4}+\varepsilon$ & $(25)$ \\
\hline$V=\beta_{0}+\mathrm{e}^{\left(\beta_{1}+\beta_{2}\left(d /\left(\beta_{3}+d\right)\right)\right)}+\varepsilon$ &
\end{tabular}

Ek Tablo 2. Test edilen çift girişli model formları

Annex 2. Tested double-entry model forms

\begin{tabular}{ll}
\hline$V=\beta_{1} d^{2} h+\varepsilon$ & $(26)$ \\
\hline$V=\beta_{0}+\beta_{1} d^{2} h+\varepsilon$ & $(27)$ \\
\hline$V=\beta_{0}+\beta_{1} d^{2}+\beta_{2} h+\beta_{3} d^{2} h+\varepsilon$ & $(28)$ \\
\hline$V=d^{2}\left(\beta_{0}+\beta_{1} h^{-1}\right)^{-1}+\varepsilon$ & $(29)$ \\
\hline$V=d^{2}\left(\beta_{0}+\beta_{1} h\right)^{-1}+\varepsilon$ & $(30)$ \\
\hline$V=\beta_{1} d^{2}+h\left(\beta_{2} h+\beta_{3} d h+\beta_{4} d^{2}\right)+\varepsilon$ & $(31)$ \\
\hline$V=\beta_{0}+\beta_{1} d+\beta_{2} d^{2}+h\left(\beta_{3}+\beta_{4} d+\beta_{5} d^{2}\right)+\varepsilon$ & $(32)$ \\
\hline$V=\beta_{0}+\beta_{1} d+\beta_{2} d^{2}+h\left(\beta_{3} d+\beta_{4} d^{2}\right)+\varepsilon$ & $(33)$ \\
\hline$V=d^{2} h\left(\beta_{0}+\beta_{1} d\right)^{-1}+\varepsilon$ & $(34)$ \\
\hline$V=\beta_{0}+\beta_{1} d^{2}+h\left(\beta_{2} h+\beta_{3} d h+\beta_{4} d^{2} h\right)+\varepsilon$ & $(35)$ \\
\hline $\log V=\beta_{0}+\beta_{1} \log d+\beta_{2} \log d+\varepsilon$ & $(36)$ \\
\hline $\log V=\beta_{0}+\beta_{1} \log \left(d^{2} h\right)+\varepsilon$ & $(37)$ \\
\hline $\log V=\beta_{0}+\beta_{1} \log d+\beta_{2}(\log d)^{2}+\beta_{3} \log d+\beta_{4}(\operatorname{logh})^{2}+\varepsilon$ & $(38)$ \\
\hline$V=\beta_{0} d_{1} h_{2}+\varepsilon$ & $(39)$ \\
\hline$V=d^{2}\left(\beta_{0}+\beta_{1} h\right)+\varepsilon$ & $(40)$ \\
\hline$V=\beta_{1} d^{2}+\beta_{2} d h^{2}+\beta_{3} d^{2} h+\varepsilon$ & $(41)$ \\
\hline$V=\beta_{0}+\beta_{1} d+\beta_{2} d^{2}+\beta_{3} h+\beta_{4} d^{2} h+\varepsilon$ & $(42)$ \\
\hline$V=d^{2} /\left(\beta_{0}+\beta_{1} h^{-1}\right)+\varepsilon$ & $(43)$ \\
\hline $\log V=\beta_{0}+\beta_{1}(\log d)^{2}+\beta_{2}(\log h)^{2}+\varepsilon$ & $(46)$ \\
\hline$V=\beta_{0}+\beta_{1} d^{2}+\beta_{2} d^{2} h+\beta_{3} d h^{2}+\varepsilon$ & $(40)$ \\
\hline$V=\beta_{1} d+\beta_{2} d^{2}+\beta_{3} h+\beta_{4} d h+\beta_{5} d^{2} h+\varepsilon$ \\
\hline$V=\beta_{1} d+\beta_{2} d^{2}+\beta_{3} d h+\beta_{4} d^{2} h+\varepsilon$ & \\
\hline$V=\beta_{1} d^{2}+\beta_{2} d h^{2}+\beta_{3} d^{2} h^{2}+\varepsilon$ & $(43)$ \\
\hline $\log V=\beta_{0}+\beta_{1} \log d+\beta_{2} \log h+\beta_{3}(l / d)+\varepsilon$ & $(40)$ \\
\hline $\log V=\beta_{0}+\beta_{1}(\log d)^{4}+\beta_{2} \log h+\varepsilon$ & \\
\hline
\end{tabular}

\begin{tabular}{|c|c|}
\hline $\log V=\beta_{0}+\beta_{1}(\log d)^{4}+\beta_{2}(\log h)^{4}+\varepsilon$ & (51) \\
\hline $\log V=\beta_{0}+\beta_{1}(\log d)^{2}+\beta_{2} \log h+\varepsilon$ & $(52)$ \\
\hline $\log V=\beta_{0}+\beta_{1} d+\beta_{2} H+\beta_{3} d^{2}+\beta_{4} h^{2}+\beta_{5} d h^{2}+\beta_{6} d^{2} h+\varepsilon$ & (53) \\
\hline$V=\beta_{1} d h+\beta_{2} d^{2} h+\varepsilon$ & $(54)$ \\
\hline $\log V=\beta_{0}+\beta_{1} \log d+\beta_{2}(\log h)^{2}+\varepsilon$ & $(55)$ \\
\hline $\log V=\beta_{0}+\beta_{1} \log d+\beta_{2}(\log h)^{4}+\varepsilon$ & $(56)$ \\
\hline $\log V=\beta_{0}+\beta_{1} \log d+\beta_{2} \log h+\beta_{3}(1 / h)+\varepsilon$ & $(57)$ \\
\hline $\log V=\beta_{0}+\beta_{l} \log d+\beta_{2} \log h+\beta_{3} d^{2}+\varepsilon$ & $(58)$ \\
\hline $\log V=\beta_{0}+\beta_{1} \log d+\beta_{2} \log h+\beta_{3} d^{2} h+\varepsilon$ & $(59)$ \\
\hline $\log V=\beta_{0}+\beta_{1} \log d+\beta_{2} \log h+\beta_{3} h^{2}+\varepsilon$ & $(60)$ \\
\hline $\log V=\beta_{0}+\beta_{1} \log d+\beta_{2} \log h+\beta_{3} d h^{2}+\varepsilon$ & $(61)$ \\
\hline $\log V=\beta_{0}+\beta_{1}(\log d)^{2}+\beta_{2} h+\varepsilon$ & $(62)$ \\
\hline $\log V=\beta_{0}+\beta_{1}(\log d)^{4}+\beta_{2} h+\varepsilon$ & (63) \\
\hline $\log V=\beta_{0}+\beta_{1}(\log d)^{4}+\beta_{2} h+\beta_{3}(1 / h)^{2}+\varepsilon$ & (64) \\
\hline $\begin{aligned} \log V= & \beta_{0}+\beta_{1}(\log d)^{4}+\beta_{2} h+\beta_{3}(1 / h)^{2}+\beta_{4}(1 / h)+ \\
& \beta_{5}(1 / d)^{2}+\varepsilon\end{aligned}$ & $(65)$ \\
\hline $\begin{aligned} \log V= & \beta_{0}+\beta_{1}(\log d)^{4}+\beta_{2} h+\beta_{3}(1 / h)^{2}+\beta_{4}(1 / h)+ \\
& \beta_{5}(1 / d)^{2}+\beta_{6}(l / d)+\varepsilon\end{aligned}$ & $(66)$ \\
\hline$V=\beta_{0}+\beta_{1} d^{\beta_{2} h^{\beta_{3}}+\varepsilon}$ & $(67)$ \\
\hline$V=\beta_{0} d^{\beta_{1}} h^{\left(3-\beta_{1}\right)}+\varepsilon$ & $(68)$ \\
\hline$V=\beta_{0} d^{\beta_{1}}\left(h^{2} /(h-1.3)\right)^{\beta_{2}+\varepsilon}$ & (69) \\
\hline$V^{(1 / 2)}=\beta_{0}+\beta_{1} d^{2}+\beta_{2} h+\varepsilon$ & $(70)$ \\
\hline$V=\beta_{0}+\beta_{1} h+\beta_{2}(d / h)+\beta_{3} d+\beta_{4} d h+\beta_{5}(l / h)+\varepsilon$ & $(71)$ \\
\hline$V=\beta_{0}+\beta_{1} d+\beta_{2}(l / d)+\beta_{3} d^{2} h+\beta_{4} d^{2} h^{2}+\varepsilon$ & $(72)$ \\
\hline $\begin{aligned} \log V= & \beta_{0}+\beta_{1} d+\beta_{2} d^{-1}+\beta_{3} h^{-1}+\beta_{4}(d / h)+\beta_{5} d^{-2}+ \\
& \beta_{6} \log \left(d^{2} h\right)+\varepsilon\end{aligned}$ & (73) \\
\hline $\log V=\beta_{0}+\beta_{1}(1 / d)+\beta_{2}\left(1 / d^{2} h^{2}\right)+\beta_{3} \log \left(d^{2} h\right)+\varepsilon$ & (74) \\
\hline $\log V=\beta_{0}+\beta_{1} \log \left(d^{2} h\right)+\beta_{2}(1 / h+6)^{2}+\beta_{3}(1 / d h)+\varepsilon$ & $(75)$ \\
\hline
\end{tabular}


Ek Tablo 3. İzmir OBM tek girişli gövde hacim denklemlerine ilişkin regresyon parametre (katsayı) değerleri Annex 3. Regression coefficient values for Izmir RDF single-input tree volume equations

\begin{tabular}{|c|c|c|c|c|c|c|c|}
\hline \multirow{2}{*}{$\begin{array}{c}\text { Model } \\
\text { No }\end{array}$} & \multicolumn{5}{|c|}{ Katsayılar } & \multirow{2}{*}{$\mathrm{SE}$} & \multirow{2}{*}{$\mathrm{DF}(f)$} \\
\hline & $\beta_{0}$ & $\beta_{1}$ & $\beta_{2}$ & $\beta_{3}$ & $\beta_{4}$ & & \\
\hline \multirow{2}{*}{01} & $-0,278033$ & 0,000870 & & & & & \\
\hline & $* * *$ & $* * *$ & & & & & \\
\hline \multirow[t]{2}{*}{02} & 0,231461 & $-0,029548$ & 0,001163 & & & & \\
\hline & $* * *$ & $* * *$ & $* * *$ & & & & \\
\hline \multirow{2}{*}{03} & & $-0,018312$ & 0,001060 & & & & \\
\hline & & $* * *$ & $* * *$ & & & & \\
\hline \multirow{2}{*}{04} & $-4,203748$ & 2,577248 & & & & 0,087966 & 1,0207248456 \\
\hline & $* * *$ & $* * *$ & & & & & \\
\hline \multirow{2}{*}{05} & $-4,710408$ & 2,848636 & 2,593808 & & & 0,082142 & 1,0180477377 \\
\hline & $* * *$ & $* * *$ & $* * *$ & & & & \\
\hline \multirow{2}{*}{06} & $-3,945083$ & 2,322701 & 0,020361 & & & 0,084860 & 1,0192734167 \\
\hline & *** & $* * *$ & *** & & & & \\
\hline \multirow{2}{*}{07} & $-9,679488$ & 2,577248 & & & & 0,202548 & 1,0207247101 \\
\hline & $* * *$ & $* * *$ & & & & & \\
\hline \multirow{2}{*}{08} & $-10,846115$ & 2,848636 & 5,972464 & & & 0,189139 & 1,0180476198 \\
\hline & $* * *$ & $* * *$ & $* * *$ & & & & \\
\hline \multirow[t]{2}{*}{09} & $-9,083890$ & 2,322701 & 0,001668 & & & 0,195397 & 1,0192732907 \\
\hline & *** & $* * *$ & $* * *$ & & & & \\
\hline \multirow{2}{*}{10} & $-5,450945$ & 3,388001 & $-0,025049$ & 4,755827 & & 0.081391 & 1.0177162155 \\
\hline & *** & $* * *$ & $*$ & $* * *$ & & & \\
\hline 11 & $-4,012508$ & 0,480799 & & & & & \\
\hline 12 & & 0,000108 & 2,460254 & & & & \\
\hline 13 & $-0,054938$ & 0,000140 & 2,404347 & & & & \\
\hline 14 & $-5,376814$ & 10,695028 & 41,313276 & & & & \\
\hline \multirow[t]{2}{*}{15} & 0,403339 & $-0,034528$ & 0,001200 & $-1,419072$ & & & \\
\hline & $*$ & *** & $* * *$ & NS & & & \\
\hline \multirow{2}{*}{16} & $-5,597213$ & 0,390884 & & & & 0,235538 & 1,0281273478 \\
\hline & $* * *$ & $* * *$ & & & & & \\
\hline \multirow[t]{2}{*}{17} & $-2,430839$ & 0,900044 & & & & 0,102293 & 1,0281275324 \\
\hline & *** & $* * *$ & & & & & \\
\hline \multirow[t]{2}{*}{18} & $-1,699920$ & 0,010294 & $-21,682721$ & & & 0,255751 & 1,0332448425 \\
\hline & $\begin{array}{c}* * * \\
-0,738266\end{array}$ & $\frac{* * *}{0,125664}$ & $\begin{array}{c}* * * * \\
-9,416686\end{array}$ & & & 0,111071 & 10332450613 \\
\hline 19 & $* * *$ & $* * *$ & $* * *$ & & & & \\
\hline 20 & $-6,447681$ & 0,554955 & $-0,006853$ & & & 0,186313 & 1,0175077860 \\
\hline & *** & *** & *** & & & & \\
\hline 21 & $-2,800192$ & 1,277831 & $-0,083666$ & & & 0,080915 & 1,0175079003 \\
\hline & $* * *$ & $* * *$ & $* * *$ & & & & \\
\hline 22 & $-0,238602$ & 0,030895 & & & & & \\
\hline & *** & $* * *$ & & & & & \\
\hline 23 & 0,137614 & $-0,020474$ & 0,000945 & 0,000001 & & & \\
\hline & NS & $*$ & $* * *$ & NS & & & \\
\hline 24 & 0,284688 & $-0,040068$ & 0,001714 & $-0,000010$ & 0,00000005 & & \\
\hline & NS & $*$ & $*$ & NS & NS & & \\
\hline 25 & $-0,072327$ & $-4,238380$ & 9,906247 & 53,840795 & & & \\
\hline
\end{tabular}


Ek Tablo 4. İzmir OBM çift girişli gövde hacim denklemlerine ilişkin regresyon parametre (katsayı) değerleri Annex 4. Regression coefficient values for Izmir RDF double-input tree volume equations

\begin{tabular}{|c|c|c|c|c|c|c|c|c|c|}
\hline \multirow{2}{*}{$\begin{array}{c}\text { Model } \\
\text { No }\end{array}$} & \multicolumn{7}{|c|}{ Katsayılar } & \multirow{2}{*}{ SE } & \multirow{2}{*}{$\mathrm{DF}(f)$} \\
\hline & $\beta_{0}$ & $\beta_{1}$ & $\beta_{2}$ & $\beta_{3}$ & $\beta_{4}$ & $\beta_{5}$ & $\beta_{6}$ & & \\
\hline \multirow{2}{*}{26} & & 0,000038 & & & & & & & \\
\hline & & $* * *$ & & & & & & & \\
\hline \multirow{2}{*}{27} & 0,000014 & 0,000038 & & & & & & & \\
\hline & NS & $* * *$ & & & & & & & \\
\hline \multirow{2}{*}{28} & 0,007702 & $-0,000169$ & 0,005766 & 0,000044 & & & & & \\
\hline & NS & $* * *$ & NS & $* * *$ & & & & & \\
\hline 29 & $-182,657765$ & 30832,197 & & & & & & & \\
\hline 30 & 2779,448549 & $-69,27306$ & & & & & & & \\
\hline 31 & & $-0,000076$ & $-0,000234$ & 0,000020 & 0,000036 & & & & \\
\hline 32 & $-0,048860$ & 0,019965 & $-0,000513$ & $-0,024679$ & 0,000160 & 0,000052 & & & \\
\hline 33 & $-0,141151$ & 0,017326 & $-0,000438$ & $-0,000364$ & 0,000053 & & & & \\
\hline 34 & 26654,91699 & 0,118193 & & & & & & & \\
\hline 35 & 0,014167 & 0,000250 & $-0,000897$ & 0,000042 & 0,000001 & & & & \\
\hline & $-4,138185$ & 2,024549 & 0,714720 & & & & & 0,06117 & 1,009969336 \\
\hline 36 & $* * *$ & $* * *$ & $* * *$ & & & & & & \\
\hline 37 & $-4,108199$ & 0,926614 & & & & & & 0,06390 & 1,010882196 \\
\hline & $* * *$ & $* * *$ & & & & & & & \\
\hline 38 & $-3,415531$ & 1,707028 & 0,081957 & $-0,369999$ & 0,606765 & & & 0,04356 & 1,005043299 \\
\hline & $* * *$ & $* * *$ & NS & $*$ & $* * *$ & & & & \\
\hline 39 & 0,000026 & 1,877340 & 1,292980 & & & & & & \\
\hline 40 & $-0,000074$ & 0,000041 & & & & & & & \\
\hline 41 & & $-0,000099$ & 0,000013 & 0,000038 & & & & & \\
\hline & & $* * *$ & $* *$ & $* * *$ & & & & & \\
\hline 42 & $-0,080591$ & 0,021573 & $-0,000526$ & $-0,021003$ & 0,000053 & & & & \\
\hline & $*$ & $* * *$ & $* * *$ & $* *$ & $* * *$ & & & & \\
\hline 43 & $-182,657694$ & 30832,194 & & & & & & & \\
\hline 44 & $-2,408075$ & 0,653233 & 0,463108 & & & & & 0,06453 & 1,011100459 \\
\hline & $* * *$ & $* * *$ & $* * *$ & & & & & & \\
\hline 45 & 0,035379 & $-0,000142$ & 0,000041 & 0,000010 & & & & & \\
\hline & NS & $* * *$ & $* * *$ & $*$ & & & & & \\
\hline 46 & & 0,017133 & $-0,000482$ & $-0,028329$ & 0,000339 & 0,000050 & & & \\
\hline & & $* * *$ & $* * *$ & $* *$ & $*$ & $* * *$ & & & \\
\hline 47 & & 0,004405 & $-0,000269$ & 0,000042 & 0,000046 & & & & \\
\hline & & $*$ & $* * *$ & NS & $* * *$ & & & & \\
\hline 48 & & 0,000247 & 0,000016 & 0,000001 & & & & & \\
\hline & & $* * *$ & $* * *$ & $* * *$ & & & & & \\
\hline 49 & $-4,774833$ & 2,324356 & 0,771624 & 3,286001 & & & & 0,04618 & 1,005669200 \\
\hline & $* * *$ & $* * *$ & $* * *$ & $* * *$ & & & & & \\
\hline 50 & $-2,657666$ & 0,101122 & 1,592452 & & & & & 0,11379 & 1,034919598 \\
\hline & $* * *$ & $* * *$ & $* * *$ & & & & & & \\
\hline 51 & $-1,508780$ & 0,112422 & 0,292133 & & & & & 0,19169 & 1,102313269 \\
\hline & $* * *$ & $* * *$ & $* * *$ & & & & & & \\
\hline 52 & $-2,834573$ & 0,659047 & 0,903245 & & & & & 0,05418 & 1,007810958 \\
\hline & $* * *$ & $* * *$ & $* * *$ & & & & & & \\
\hline 53 & $-2,505145$ & 0,069744 & 0,070198 & $-0,000818$ & $-0,001099$ & $-0,000050$ & 0,000027 & 0,05905 & 1,009285158 \\
\hline & $* * *$ & $* * *$ & $* * *$ & $* * *$ & NS & $* * *$ & $* * *$ & & \\
\hline 54 & & $-0,000001$ & 0,000038 & & & & & & \\
\hline & & NS & $* * *$ & & & & & & \\
\hline 55 & $-3,728928$ & 1,916472 & 0,433951 & & & & & 0,04717 & 1,005914561 \\
\hline & $* * *$ & $* * *$ & $* * *$ & & & & & & \\
\hline 56 & $-3,649277$ & 2,029828 & 0,164446 & & & & & 0,04997 & 1,006641043 \\
\hline & $* * *$ & $* * *$ & $* * *$ & & & & & & \\
\hline 57 & $-4,947764$ & 1,955487 & 1,374380 & 2,128241 & & & & 0,04272 & 1,004848965 \\
\hline & $* * *$ & $* * *$ & $* * *$ & $* * *$ & & & & & \\
\hline 58 & $-3,978570$ & 1,844277 & 0,776803 & 0,000022 & & & & 0,05505 & 1,008065196 \\
\hline & $* * *$ & $* * *$ & $* * *$ & $* * *$ & & & & & \\
\hline 59 & $-4,008922$ & 1,890098 & 0,753593 & 0,000001 & & & & 0,05525 & 1,008125287 \\
\hline & $* * *$ & $* * *$ & $* * *$ & $* * *$ & & & & & \\
\hline
\end{tabular}

$\mathrm{NS}=P>0.05, *=0.01<P<0.05, * *=0.001<P<0.01, * * *=P<0.001$ 
Ek Tablo 4. İzmir OBM çift girişli gövde hacim denklemlerine ilişkin regresyon parametre (katsayı) değerleri Annex 4. Regression coefficient values for Izmir RDF double-input tree volume equations

\begin{tabular}{|c|c|c|c|c|c|c|c|c|c|}
\hline $\begin{array}{c}\text { Model } \\
\text { No }\end{array}$ & & & & Katsayılar & & & & $\mathrm{SE}$ & $\mathrm{DF}(f)$ \\
\hline \multirow{2}{*}{60} & $-3,874979$ & 1,925071 & 0,502698 & 0,000537 & & & & 0,04813 & 1,006159728 \\
\hline & $* * *$ & $* * *$ & $* * *$ & $* * *$ & & & & & \\
\hline \multirow{2}{*}{61} & $-3,967394$ & 1,884844 & 0,707860 & 0,000004 & & & & 0,05249 & 1,007329481 \\
\hline & *** & $* * *$ & $* * *$ & $* * *$ & & & & & \\
\hline \multirow{2}{*}{62} & $-2,359783$ & 0,712675 & 0,027625 & & & & & 0,08372 & 1,018753749 \\
\hline & $* * *$ & $* * *$ & $* * *$ & & & & & & \\
\hline \multirow{2}{*}{63} & $-1,756734$ & 0,098890 & 0,061177 & & & & & 0,17414 & 1,083710930 \\
\hline & $* * *$ & $* * *$ & $* * *$ & & & & & & \\
\hline \multirow[t]{2}{*}{64} & $-1,384190$ & 0,113984 & 0,033446 & $-7,105206$ & & & & 0,12423 & 1,041759526 \\
\hline & $* * *$ & $* * *$ & $* * *$ & $* * *$ & & & & & \\
\hline \multirow{2}{*}{65} & $-0,177089$ & 0,108782 & $-0,003733$ & 19,684943 & $-9,668224$ & $-35,24309$ & & 0,07072 & 1,013347181 \\
\hline & $* *$ & $* * *$ & NS & $* * *$ & $* * *$ & $* * *$ & & & \\
\hline \multirow{2}{*}{66} & $-0,310474$ & 0,066545 & 0,021134 & 5,726290 & $-2,881060$ & 35,675703 & $-14,97627$ & 0,04626 & 1,005689951 \\
\hline & $* * *$ & $* * *$ & $* * *$ & $* * *$ & $* * *$ & $* * *$ & $* * *$ & & \\
\hline 67 & 0,024318 & 0,000022 & 1,889884 & 1,318930 & & & & & \\
\hline 68 & 0,000042 & 1,917076 & & & & & & & \\
\hline 69 & 0.000017 & 1.874668 & 1.397818 & & & & & & \\
\hline \multirow{2}{*}{70} & $-0,074716$ & 0,000212 & 0,044163 & & & & & & \\
\hline & $* * *$ & $* * *$ & $* * *$ & & & & & & \\
\hline \multirow{2}{*}{71} & 3,041891 & $-0,273723$ & $-0,048451$ & $-0,047044$ & 0,007210 & $-6,278502$ & & & \\
\hline & $* * *$ & $* * *$ & NS & $* * *$ & $* * *$ & $* * *$ & & & \\
\hline \multirow{2}{*}{72} & $-0,331935$ & 0,015340 & 1,806650 & 0,000010 & 0,000001 & & & & \\
\hline & $* *$ & $* * *$ & $*$ & $*$ & $* * *$ & & & & \\
\hline \multirow{2}{*}{73} & $-4,920604$ & 0,000448 & 0,968492 & 1,738356 & $-0,031043$ & $-1,379439$ & 1,093248 & 0,04235 & 1,004764981 \\
\hline & $* * *$ & NS & NS & $* * *$ & NS & NS & $* * *$ & & \\
\hline \multirow[t]{2}{*}{75} & $-4,634841$ & 1,035072 & 15,868693 & 5,413722 & & & & 0,04297 & 1,004907600 \\
\hline & $* * *$ & $* * *$ & $* * *$ & $* * *$ & & & & & \\
\hline
\end{tabular}

$\mathrm{NS}=P>0.05, *=0.01<P<0.05, * *=0.001<P<0.01, * * *=P<0.001$ 
Ek Tablo 5a. İzmir OBM Fıstıkçamı (Pinus pinea L.) Çift Girişli DKGHT Annex 5a. Izmir RDF Stone Pine (Pinus pinea L.) Double Entry Volume Table

\begin{tabular}{|c|}
\hline $\begin{array}{c}\text { Göğüs çap1 } \\
\text { (cm) }\end{array}$ \\
\hline 6 \\
\hline 8 \\
\hline 10 \\
\hline 12 \\
\hline 14 \\
\hline 16 \\
\hline 18 \\
\hline 20 \\
\hline 22 \\
\hline 24 \\
\hline 26 \\
\hline 28 \\
\hline 30 \\
\hline 32 \\
\hline 34 \\
\hline 36 \\
\hline 38 \\
\hline 40 \\
\hline 42 \\
\hline 44 \\
\hline 46 \\
\hline 48 \\
\hline 50 \\
\hline 52 \\
\hline 54 \\
\hline 56 \\
\hline 58 \\
\hline 60 \\
\hline 62 \\
\hline 64 \\
\hline 66 \\
\hline 68 \\
\hline 70 \\
\hline 72 \\
\hline 74 \\
\hline 76 \\
\hline 78 \\
\hline 80 \\
\hline 82 \\
\hline 84 \\
\hline 86 \\
\hline 88 \\
\hline 90 \\
\hline 92 \\
\hline 94 \\
\hline 96 \\
\hline 98 \\
\hline 100 \\
\hline 102 \\
\hline 104 \\
\hline
\end{tabular}

\begin{tabular}{|c|c|c|c|c|c|c|c|c|c|c|}
\hline \multicolumn{11}{|c|}{ Ağaç boyu (m) } \\
\hline 2 & 3 & 4 & 5 & 6 & 7 & 8 & 9 & 10 & 11 & 12 \\
\hline & 0,0093 & 0,0097 & 0,0103 & 0,0111 & 0,0119 & 0,0128 & 0,0137 & 0,0146 & & \\
\hline 0,0136 & 0,0142 & 0,0154 & 0,0169 & 0,0184 & 0,0201 & 0,0217 & 0,0235 & 0,0252 & 0,0270 & 0,0288 \\
\hline 0,0185 & 0,0203 & 0,0226 & 0,0251 & 0,0278 & 0,0304 & 0,0332 & 0,0360 & 0,0388 & 0,0416 & 0,0445 \\
\hline 0,0243 & 0,0276 & 0,0313 & 0,0352 & 0,0391 & 0,0431 & 0,0471 & 0,0513 & 0,0554 & 0,0596 & 0,0638 \\
\hline 0,0311 & 0,0362 & 0,0415 & 0,0470 & 0,0525 & 0,0581 & 0,0637 & 0,0694 & 0,0751 & 0,0809 & 0,0867 \\
\hline 0,0388 & 0,0460 & 0,0533 & 0,0606 & 0,0679 & 0,0753 & 0,0828 & 0,0903 & 0,0979 & 0,1056 & 0,1133 \\
\hline 0,0474 & 0,0570 & 0,0665 & 0,0760 & 0,0854 & 0,0949 & 0,1045 & 0,1142 & 0,1239 & 0,1337 & 0,1435 \\
\hline 0,0569 & 0,0693 & 0,0813 & 0,0932 & 0,1050 & 0,1169 & 0,1289 & 0,1409 & 0,1530 & 0,1652 & 0,1775 \\
\hline & 0,0828 & 0,0977 & 0,1122 & 0,1268 & 0,1413 & 0,1559 & 0,1706 & 0,1853 & 0,2002 & 0,2152 \\
\hline & 0,0976 & 0,1156 & 0,1331 & 0,1506 & 0,1680 & 0,1855 & 0,2032 & 0,2209 & 0,2387 & 0,2566 \\
\hline & & 0,1350 & 0,1559 & 0,1765 & 0,1972 & 0,2179 & 0,2387 & 0,2596 & 0,2807 & 0,3019 \\
\hline & & 0,1561 & 0,1805 & 0,2046 & 0,2288 & 0,2529 & 0,2772 & 0,3017 & 0,3262 & 0,3509 \\
\hline & & 0,1787 & 0,2069 & 0,2349 & 0,2628 & 0,2907 & 0,3187 & 0,3469 & 0,3753 & 0,4038 \\
\hline & & & 0,2353 & 0,2673 & 0,2992 & 0,3312 & 0,3632 & 0,3955 & 0,4279 & 0,4605 \\
\hline & & & 0,2655 & 0,3019 & 0,3381 & 0,3744 & 0,4108 & 0,4474 & 0,4841 & 0,5211 \\
\hline & & & 0,2977 & 0,3387 & 0,3795 & 0,4203 & 0,4613 & 0,5025 & 0,5439 & 0,5856 \\
\hline & & & & 0,3776 & 0,4233 & 0,4690 & 0,5149 & 0,5610 & 0,6074 & 0,6540 \\
\hline & & & & & 0,4696 & 0,5205 & 0,5716 & 0,6228 & 0,6744 & 0,7262 \\
\hline & & & & & 0,5184 & 0,5748 & 0,6313 & 0,6880 & 0,7451 & 0,8024 \\
\hline & & & & & & 0,6318 & 0,6940 & 0,7565 & 0,8194 & 0,8825 \\
\hline & & & & & & 0,6916 & 0,7599 & 0,8284 & 0,8973 & 0,9666 \\
\hline & & & & & & & 0,8288 & 0,9037 & 0,9790 & 1,0546 \\
\hline & & & & & & & 0,9009 & 0,9824 & 1,0643 & 1,1466 \\
\hline & & & & & & & 0,9760 & 1,0645 & 1,1533 & 1,2426 \\
\hline & & & & & & & & 1,1499 & 1,2460 & 1,3426 \\
\hline & & & & & & & & 1,2388 & 1,3425 & 1,4466 \\
\hline & & & & & & & & 1,3312 & 1,4426 & 1,5546 \\
\hline & & & & & & & & & 1,5465 & 1,6666 \\
\hline & & & & & & & & & 1,6541 & 1,7827 \\
\hline & & & & & & & & & & 1,9028 \\
\hline & & & & & & & & & & 2,0270 \\
\hline & & & & & & & & & & 2,1552 \\
\hline & & & & & & & & & & \\
\hline & & & & & & & & & & \\
\hline & & & & & & & & & & \\
\hline & & & & & & & & & & \\
\hline & & & & & & & & & & \\
\hline & & & & & & & & & & \\
\hline & & & & & & & & & & \\
\hline & & & & & & & & & & \\
\hline & & & & & & & & & & \\
\hline & & & & & & & & & & \\
\hline & & & & & & & & & & \\
\hline & & & & & & & & & & \\
\hline & & & & & & & & & & \\
\hline & & & & & & & & & & \\
\hline & & & & & & & & & & \\
\hline & & & & & & & & & & \\
\hline & & & & & & & & & & \\
\hline & & & & & & & & & & \\
\hline
\end{tabular}


Ek Tablo 5b. İzmir OBM Fıstıkçamı (Pinus pinea L.) Çift Girişli DKGHT

Annex 5b. Izmir RDF Stone Pine (Pinus pinea L.) Double Entry Volume Table

\begin{tabular}{|c|}
\hline $\begin{array}{l}\text { Göğüs çap1 } \\
\text { (cm) }\end{array}$ \\
\hline 14 \\
\hline 16 \\
\hline 18 \\
\hline 20 \\
\hline 22 \\
\hline 24 \\
\hline 26 \\
\hline 28 \\
\hline 30 \\
\hline 32 \\
\hline 34 \\
\hline 36 \\
\hline 38 \\
\hline 40 \\
\hline 42 \\
\hline 44 \\
\hline 46 \\
\hline 48 \\
\hline 50 \\
\hline 52 \\
\hline 54 \\
\hline 56 \\
\hline 58 \\
\hline 60 \\
\hline 62 \\
\hline 64 \\
\hline 66 \\
\hline 68 \\
\hline 70 \\
\hline 72 \\
\hline 74 \\
\hline 76 \\
\hline 78 \\
\hline 80 \\
\hline 82 \\
\hline 84 \\
\hline 86 \\
\hline 88 \\
\hline 90 \\
\hline 92 \\
\hline 94 \\
\hline 96 \\
\hline 98 \\
\hline 100 \\
\hline 102 \\
\hline 104 \\
\hline 106 \\
\hline 108 \\
\hline 110 \\
\hline 112 \\
\hline
\end{tabular}

\begin{tabular}{|c|c|c|c|c|c|c|c|c|c|c|}
\hline \multicolumn{11}{|c|}{ Ağaç boyu (m) } \\
\hline 13 & 14 & 15 & 16 & 17 & 18 & 19 & 20 & 21 & 22 & 23 \\
\hline 0,0926 & 0,0985 & 0,1045 & & & & & & & & \\
\hline 0,1211 & 0,1289 & 0,1367 & 0,1446 & & & & & & & \\
\hline 0,1535 & 0,1634 & 0,1735 & 0,1836 & 0,1937 & & & & & & \\
\hline 0,1898 & 0,2023 & 0,2148 & 0,2273 & 0,2400 & 0,2526 & & & & & \\
\hline 0,2302 & 0,2454 & 0,2606 & 0,2759 & 0,2913 & 0,3068 & 0,3223 & & & & \\
\hline 0,2747 & 0,2928 & 0,3111 & 0,3294 & 0,3478 & 0,3664 & 0,3849 & 0,4036 & & & \\
\hline 0,3232 & 0,3446 & 0,3662 & 0,3878 & 0,4096 & 0,4314 & 0,4534 & 0,4754 & 0,4975 & & \\
\hline 0,3758 & 0,4008 & 0,4259 & 0,4512 & 0,4765 & 0,5020 & 0,5276 & 0,5532 & 0,5790 & & \\
\hline 0,4325 & 0,4613 & 0,4903 & 0,5195 & 0,5487 & 0,5781 & 0,6076 & 0,6372 & 0,6669 & & \\
\hline 0,4933 & 0,5263 & 0,5595 & 0,5928 & 0,6262 & 0,6598 & 0,6935 & 0,7274 & 0,7613 & 0,7954 & \\
\hline 0,5583 & 0,5957 & 0,6333 & 0,6711 & 0,7090 & 0,7471 & 0,7853 & 0,8237 & 0,8622 & 0,9008 & \\
\hline 0,6275 & 0,6696 & 0,7119 & 0,7544 & 0,7971 & 0,8400 & 0,8830 & 0,9262 & 0,9696 & 1,0131 & \\
\hline 0,7008 & 0,7479 & 0,7952 & 0,8428 & 0,8905 & 0,9385 & 0,9866 & 1,0350 & 1,0834 & 1,1321 & 1,1809 \\
\hline 0,7783 & 0,8307 & 0,8833 & 0,9362 & 0,9893 & 1,0427 & 1,0962 & 1,1500 & 1,2039 & 1,2580 & 1,3123 \\
\hline 0,8601 & 0,9180 & 0,9762 & 1,0348 & 1,0935 & 1,1525 & 1,2118 & 1,2712 & 1,3309 & 1,3907 & 1,4508 \\
\hline 0,9460 & 1,0098 & 1,0740 & 1,1384 & 1,2031 & 1,2681 & 1,3333 & 1,3988 & 1,4645 & 1,5304 & 1,5965 \\
\hline 1,0362 & 1,1062 & 1,1765 & 1,2472 & 1,3181 & 1,3894 & 1,4609 & 1,5327 & 1,6047 & 1,6770 & 1,7495 \\
\hline 1,1307 & 1,2071 & 1,2839 & 1,3611 & 1,4386 & 1,5164 & 1,5945 & 1,6729 & 1,7516 & 1,8305 & 1,9097 \\
\hline 1,2294 & 1,3126 & 1,3962 & 1,4801 & 1,5645 & 1,6492 & 1,7342 & 1,8195 & 1,9051 & 1,9910 & 2,0771 \\
\hline 1,3324 & 1,4226 & 1,5133 & 1,6044 & 1,6958 & 1,7877 & 1,8799 & 1,9724 & 2,0653 & 2,1584 & 2,2519 \\
\hline 1,4397 & 1,5373 & 1,6353 & 1,7338 & 1,8327 & 1,9320 & 2,0317 & 2,1318 & 2,2322 & 2,3329 & 2,4339 \\
\hline 1,5513 & 1,6565 & 1,7622 & 1,8684 & 1,9750 & 2,0821 & 2,1896 & 2,2975 & 2,4057 & 2,5143 & 2,6233 \\
\hline 1,6672 & 1,7803 & 1,8940 & 2,0082 & 2,1229 & 2,2380 & 2,3536 & 2,4697 & 2,5861 & 2,7029 & 2,8200 \\
\hline 1,7874 & 1,9088 & 2,0307 & 2,1532 & 2,2763 & 2,3998 & 2,5238 & 2,6483 & 2,7731 & 2,8984 & 3,0241 \\
\hline 1,9120 & 2,0419 & 2,1724 & 2,3035 & 2,4352 & 2,5674 & 2,7001 & 2,8333 & 2,9670 & 3,1010 & 3,2355 \\
\hline 2,0409 & 2,1796 & 2,3190 & 2,4590 & 2,5996 & 2,7408 & 2,8826 & 3,0248 & 3,1676 & 3,3108 & 3,4544 \\
\hline 2,1741 & 2,3220 & 2,4706 & 2,6198 & 2,7697 & 2,9202 & 3,0712 & 3,2228 & 3,3750 & 3,5276 & 3,6807 \\
\hline & 2,4690 & 2,6271 & 2,7858 & 2,9453 & 3,1054 & 3,2661 & 3,4273 & 3,5892 & 3,7515 & 3,9143 \\
\hline & 2,6207 & 2,7886 & 2,9572 & 3,1265 & 3,2965 & 3,4671 & 3,6384 & 3,8102 & 3,9826 & 4,1555 \\
\hline & 2,7771 & 2,9551 & 3,1338 & 3,3133 & 3,4935 & 3,6743 & 3,8559 & 4,0380 & 4,2208 & 4,4041 \\
\hline & 2,9382 & 3,1265 & 3,3157 & 3,5056 & 3,6964 & 3,8878 & 4,0800 & 4,2728 & 4,4662 & 4,6602 \\
\hline & & 3,3030 & 3,5029 & 3,7037 & 3,9052 & 4,1075 & 4,3106 & 4,5143 & 4,7187 & 4,9237 \\
\hline & & 3,4845 & 3,6955 & 3,9073 & 4,1200 & 4,3335 & 4,5478 & 4,7628 & 4,9784 & 5,1948 \\
\hline & & 3,6710 & 3,8933 & 4,1166 & 4,3407 & 4,5657 & 4,7915 & 5,0181 & 5,2454 & 5,4733 \\
\hline & & 3,8626 & 4,0966 & 4,3315 & 4,5674 & 4,8042 & 5,0419 & 5,2803 & 5,5195 & 5,7595 \\
\hline & & 4,0592 & 4,3051 & 4,5521 & 4,8001 & 5,0490 & 5,2988 & 5,5494 & 5,8009 & 6,0531 \\
\hline & & 4,2608 & 4,5191 & 4,7784 & 5,0387 & 5,3001 & 5,5623 & 5,8255 & 6,0895 & 6,3543 \\
\hline & & & 4,7383 & 5,0103 & 5,2834 & 5,5574 & 5,8325 & 6,1085 & 6,3854 & 6,6631 \\
\hline & & & 4,9630 & 5,2479 & 5,5340 & 5,8211 & 6,1093 & 6,3984 & 6,6885 & 6,9794 \\
\hline & & & 5,1931 & 5,4912 & 5,7906 & 6,0911 & 6,3927 & 6,6953 & 6,9989 & 7,3034 \\
\hline & & & 5,4285 & 5,7403 & 6,0533 & 6,3675 & 6,6828 & 6,9992 & 7,3166 & 7,6349 \\
\hline & & & & 5,9950 & 6,3220 & 6,6502 & 6,9795 & 7,3100 & 7,6415 & 7,9741 \\
\hline & & & & 6,2555 & 6,5967 & 6,9392 & 7,2829 & 7,6278 & 7,9738 & 8,3208 \\
\hline & & & & 6,5217 & 6,8775 & 7,2346 & 7,5930 & 7,9526 & 8,3134 & 8,6753 \\
\hline & & & & 6,7936 & 7,1643 & 7,5364 & 7,9098 & 8,2845 & 8,6603 & 9,0373 \\
\hline & & & & & 7,4572 & 7,8445 & 8,2333 & 8,6233 & 9,0146 & 9,4070 \\
\hline & & & & & 7,7561 & 8,1591 & 8,5634 & 8,9692 & 9,3762 & 9,7844 \\
\hline & & & & & 8,0612 & 8,4800 & 8,9003 & 9,3221 & 9,7452 & 10,169 \\
\hline & & & & & 8,3723 & 8,8073 & 9,2439 & 9,6820 & 10,121 & 10,562 \\
\hline & & & & & 8,6895 & 9,1411 & 9,5943 & 10,049 & 10,505 & 10,962 \\
\hline
\end{tabular}


Ek Tablo 5c. İzmir OBM Fıstıkçamı (Pinus pinea L.) Cift Girişli DKGHT Annex 5c. Izmir RDF Stone Pine (Pinus pinea L.) Double Entry Volume Table

\begin{tabular}{|c|c|c|c|c|c|c|c|c|c|c|c|}
\hline \multirow{2}{*}{$\begin{array}{l}\text { Göğg̈s çap1 } \\
(\mathrm{cm})\end{array}$} & \multicolumn{11}{|c|}{ Ağaç boyu (m) } \\
\hline & 22 & 23 & 24 & 25 & 26 & 27 & 28 & 29 & 30 & 31 & 32 \\
\hline 38 & 1,1321 & 1,1809 & & & & & & & & & \\
\hline 40 & 1,2580 & 1,3123 & 1,3667 & & & & & & & & \\
\hline 42 & 1,3907 & 1,4508 & 1,5110 & 1,5714 & & & & & & & \\
\hline 44 & 1,5304 & 1,5965 & 1,6628 & 1,7293 & & & & & & & \\
\hline 46 & 1,6770 & 1,7495 & 1,8222 & 1,8951 & 1,9681 & & & & & & \\
\hline 48 & 1,8305 & 1,9097 & 1,9891 & 2,0687 & 2,1485 & & & & & & \\
\hline 50 & 1,9910 & 2,0771 & 2,1635 & 2,2501 & 2,3370 & & & & & & \\
\hline 52 & 2,1584 & 2,2519 & 2,3456 & 2,4395 & 2,5337 & & & & & & \\
\hline 54 & 2,3329 & 2,4339 & 2,5352 & 2,6368 & 2,7387 & 2,8408 & & & & & \\
\hline 56 & 2,5143 & 2,6233 & 2,7325 & 2,8421 & 2,9519 & 3,0620 & & & & & \\
\hline 58 & 2,7029 & 2,8200 & 2,9375 & 3,0553 & 3,1734 & 3,2918 & & & & & \\
\hline 60 & 2,8984 & 3,0241 & 3,1501 & 3,2765 & 3,4031 & 3,5301 & & & & & \\
\hline 62 & 3,1010 & 3,2355 & 3,3704 & 3,5056 & 3,6412 & 3,7772 & & & & & \\
\hline 64 & 3,3108 & 3,4544 & 3,5984 & 3,7429 & 3,8877 & 4,0328 & 4,1783 & & & & \\
\hline 66 & 3,5276 & 3,6807 & 3,8342 & 3,9881 & 4,1424 & 4,2971 & 4,4522 & & & & \\
\hline 68 & 3,7515 & 3,9143 & 4,0776 & 4,2414 & 4,4056 & 4,5701 & 4,7351 & & & & \\
\hline 70 & 3,9826 & 4,1555 & 4,3289 & 4,5028 & 4,6771 & 4,8518 & 5,0270 & 5,2025 & & & \\
\hline 72 & 4,2208 & 4,4041 & 4,5879 & 4,7722 & 4,9570 & 5,1422 & 5,3279 & 5,5140 & & & \\
\hline 74 & 4,4662 & 4,6602 & 4,8547 & 5,0498 & 5,2453 & 5,4414 & 5,6379 & 5,8348 & & & \\
\hline 76 & 4,7187 & 4,9237 & 5,1293 & 5,3354 & 5,5421 & 5,7493 & 5,9570 & 6,1651 & & & \\
\hline 78 & 4,9784 & 5,1948 & 5,4117 & 5,6293 & 5,8474 & 6,0660 & 6,2851 & 6,5047 & 6,7248 & & \\
\hline 80 & 5,2454 & 5,4733 & 5,7020 & 5,9312 & 6,1610 & 6,3914 & 6,6224 & 6,8538 & 7,0857 & & \\
\hline 82 & 5,5195 & 5,7595 & 6,0001 & 6,2413 & 6,4832 & 6,7257 & 6,9687 & 7,2123 & 7,4564 & & \\
\hline 84 & 5,8009 & 6,0531 & 6,3060 & 6,5596 & 6,8139 & 7,0688 & 7,3242 & 7,5803 & 7,8368 & & \\
\hline 86 & 6,0895 & 6,3543 & 6,6199 & 6,8861 & 7,1531 & 7,4207 & 7,6889 & 7,9577 & 8,2271 & 8,4970 & \\
\hline 88 & 6,3854 & 6,6631 & 6,9416 & 7,2208 & 7,5008 & 7,7814 & 8,0627 & 8,3446 & 8,6271 & 8,9102 & \\
\hline 90 & 6,6885 & 6,9794 & 7,2712 & 7,5637 & 7,8570 & 8,1510 & 8,4457 & 8,7411 & 9,0370 & 9,3336 & \\
\hline 92 & 6,9989 & 7,3034 & 7,6087 & 7,9149 & 8,2218 & 8,5295 & 8,8379 & 9,1470 & 9,4567 & 9,7671 & \\
\hline 94 & 7,3166 & 7,6349 & 7,9541 & 8,2743 & 8,5952 & 8,9169 & 9,2393 & 9,5625 & 9,8863 & 10,210 & \\
\hline 96 & 7,6415 & 7,9741 & 8,3075 & 8,6419 & 8,9771 & 9,3132 & 9,6500 & 9,9875 & 10,325 & 10,664 & \\
\hline 98 & 7,9738 & 8,3208 & 8,6689 & 9,0178 & 9,3677 & 9,7183 & 10,069 & 10,422 & 10,775 & 11,128 & 11,483 \\
\hline 100 & 8,3134 & 8,6753 & 9,0381 & 9,4020 & 9,7668 & 10,132 & 10,499 & 10,866 & 11,234 & 11,603 & 11,972 \\
\hline 102 & 8,6603 & 9,0373 & 9,4154 & 9,7945 & 10,174 & 10,555 & 10,937 & 11,320 & 11,703 & 12,087 & 12,472 \\
\hline 104 & 9,0146 & 9,4070 & 9,8006 & 10,195 & 10,590 & 10,987 & 11,385 & 11,783 & 12,182 & 12,582 & 12,983 \\
\hline 106 & 9,3762 & 9,7844 & 10,193 & 10,604 & 11,015 & 11,428 & 11,842 & 12,256 & 12,671 & 13,087 & 13,504 \\
\hline 108 & 9,7452 & 10,169 & 10,595 & 11,021 & 11,449 & 11,878 & 12,308 & 12,739 & 13,170 & 13,603 & 14,036 \\
\hline 110 & 10,121 & 10,562 & 11,004 & 11,447 & 11,891 & 12,337 & 12,783 & 13,231 & 13,679 & 14,128 & 14,579 \\
\hline 112 & 10,505 & 10,962 & 11,421 & 11,881 & 12,342 & 12,805 & 13,268 & 13,733 & 14,198 & 14,664 & 15,132 \\
\hline 114 & 10,896 & 11,370 & 11,846 & 12,324 & 12,802 & 13,282 & 13,762 & 14,244 & 14,727 & 15,211 & 15,695 \\
\hline 116 & 11,294 & 11,786 & 12,280 & 12,774 & 13,270 & 13,768 & 14,266 & 14,765 & 15,266 & 15,767 & 16,270 \\
\hline 118 & 11,700 & 12,210 & 12,721 & 13,234 & 13,748 & 14,263 & 14,779 & 15,296 & 15,815 & 16,334 & 16,855 \\
\hline 120 & 12,113 & 12,641 & 13,171 & 13,701 & 14,233 & 14,767 & 15,301 & 15,837 & 16,374 & 16,912 & 17,451 \\
\hline
\end{tabular}


Ek Tablo 6. İzmir OBM Fıstıkçamı (Pinus pinea L.) Tek Girişli DKGHT

Annex 6. Izmir RDF Stone Pine (Pinus pinea L.) Single Entry Volume Table

\begin{tabular}{|c|c|c|c|c|c|}
\hline $\begin{array}{l}\text { Göğüs çap1 } \\
\text { (cm) }\end{array}$ & $\operatorname{Hacim}\left(\mathrm{m}^{3}\right)$ & $\begin{array}{l}\text { Göğüs çap1 } \\
\text { (cm) }\end{array}$ & $\operatorname{Hacim}\left(\mathrm{m}^{3}\right)$ & $\begin{array}{l}\text { Göğüs çap1 } \\
\text { (cm) }\end{array}$ & $\operatorname{Hacim}\left(\mathrm{m}^{3}\right)$ \\
\hline 6 & 0,0095 & 43 & 1,0547 & 80 & 5,4354 \\
\hline 7 & 0,0122 & 44 & 1,1222 & 81 & 5,6109 \\
\hline 8 & 0,0156 & 45 & 1,1922 & 82 & 5,7895 \\
\hline 9 & 0,0198 & 46 & 1,2648 & 83 & 5,9713 \\
\hline 10 & 0,0248 & 47 & 1,3401 & 84 & 6,1561 \\
\hline 11 & 0,0307 & 48 & 1,4180 & 85 & 6,3441 \\
\hline 12 & 0,0376 & 49 & 1,4986 & 86 & 6,5352 \\
\hline 13 & 0,0455 & 50 & 1,5820 & 87 & 6,7294 \\
\hline 14 & 0,0545 & 51 & 1,6681 & 88 & 6,9268 \\
\hline 15 & 0,0646 & 52 & 1,7569 & 89 & 7,1272 \\
\hline 16 & 0,0760 & 53 & 1,8486 & 90 & 7,3308 \\
\hline 17 & 0,0887 & 54 & 1,9431 & 91 & 7,5375 \\
\hline 18 & 0,1027 & 55 & 2,0403 & 92 & 7,7474 \\
\hline 19 & 0,1181 & 56 & 2,1405 & 93 & 7,9603 \\
\hline 20 & 0,1351 & 57 & 2,2435 & 94 & 8,1763 \\
\hline 21 & 0,1536 & 58 & 2,3493 & 95 & 8,3955 \\
\hline 22 & 0,1736 & 59 & 2,4581 & 96 & 8,6178 \\
\hline 23 & 0,1954 & 60 & 2,5698 & 97 & 8,8432 \\
\hline 24 & 0,2188 & 61 & 2,6845 & 98 & 9,0717 \\
\hline 25 & 0,2440 & 62 & 2,8021 & 99 & 9,3033 \\
\hline 26 & 0,2711 & 63 & 2,9226 & 100 & 9,5380 \\
\hline 27 & 0,3000 & 64 & 3,0461 & 101 & 9,7758 \\
\hline 28 & 0,3309 & 65 & 3,1726 & 102 & 10,0167 \\
\hline 29 & 0,3637 & 66 & 3,3021 & 103 & 10,2606 \\
\hline 30 & 0,3985 & 67 & 3,4346 & 104 & 10,5077 \\
\hline 31 & 0,4354 & 68 & 3,5702 & 105 & 10,7578 \\
\hline 32 & 0,4744 & 69 & 3,7087 & 106 & 11,0110 \\
\hline 33 & 0,5156 & 70 & 3,8504 & 107 & 11,2673 \\
\hline 34 & 0,5590 & 71 & 3,9950 & 108 & 11,5267 \\
\hline 35 & 0,6046 & 72 & 4,1427 & 109 & 11,7890 \\
\hline 36 & 0,6525 & 73 & 4,2935 & 110 & 12,0545 \\
\hline 37 & 0,7027 & 74 & 4,4474 & 111 & 12,3230 \\
\hline 38 & 0,7553 & 75 & 4,6043 & 112 & 12,5945 \\
\hline 39 & 0,8103 & 76 & 4,7643 & 113 & 12,8690 \\
\hline 40 & 0,8677 & 77 & 4,9274 & 114 & 13,1466 \\
\hline 41 & 0,9275 & 78 & 5,0937 & 115 & 13,4272 \\
\hline 42 & 0,9899 & 79 & 5,2630 & 116 & 13,7108 \\
\hline
\end{tabular}

